\title{
True colors - experimental identification of hydrological processes at a hillslope prone to slide
}

\author{
P. Schneider ${ }^{1}$, S. Pool ${ }^{1}$, L. Strouhal ${ }^{1,2}$, and J. Seibert ${ }^{1,3}$ \\ ${ }^{1}$ Department of Geography, University of Zurich, Zurich, Switzerland \\ ${ }^{2}$ Faculty of Civil Engineering, Czech Technical University in Prague, Prague, Czech Republic \\ ${ }^{3}$ Department of Earth Sciences, Uppsala University, Uppsala, Sweden
}

Correspondence to: P. Schneider (philipp.schneider@geo.uzh.ch)

Received: 4 June 2013 - Published in Hydrol. Earth Syst. Sci. Discuss.: 27 June 2013

Revised: 26 December 2013 - Accepted: 7 January 2014 - Published: 28 February 2014

\begin{abstract}
This study investigated runoff formation processes of a pre-alpine hillslope prone to slide. The experimental pasture plot $(40 \mathrm{~m} \times 60 \mathrm{~m})$ is located in the northern front range of the Swiss Alps on a $30^{\circ}$ steep hillslope $(1180 \mathrm{~m}$ a.s.l., $1500+\mathrm{mm}$ annual precipitation). A gleysol (H-Go-Gr) overlies weathered marlstone and conglomerate of subalpine molasse. We conducted sprinkling experiments on a subplot $(10 \mathrm{~m} \times 10 \mathrm{~m})$ with variable rainfall intensities. During both experiments fluorescein line-tracer injections into the topsoil, and sodium chloride $(\mathrm{NaCl})$ injections into the sprinkling water were used to monitor flow velocities in the soil. The observed flow velocities for fluorescein in the soil were 1.2 and $1.4 \times 10^{-3} \mathrm{~m} \mathrm{~s}^{-1}$. The $\mathrm{NaCl}$ breakthrough occurred almost simultaneously in all monitored discharge levels ( 0.05 , 0.25 and $1.0 \mathrm{~m}$ depth), indicating a high-infiltration capacity and efficient drainage of the soil. These initial observations suggested "transmissivity feedback", a form of subsurface stormflow, as the dominant runoff process. However, the results of a brilliant blue dye tracer experiment completely changed our perceptions of the hillslope's hydrological processes. Excavation of the dye-stained soils highlighted the dominance of "organic layer interflow", a form of shallow subsurface stormflow. The dye stained the entire H horizon, vertical soil fractures, and macropores (mostly worm burrows) up to $0.5 \mathrm{~m}$ depth. Lateral drainage in the subsoil or at the soil-bedrock interface was not observed, and thus was limited to the organic topsoil. In the context of shallow landslides, the subsoil (Go/Gr) acted as an infiltration and exfiltration barrier, which produced significant lateral saturated drainage in the topsoil $(\mathrm{H})$ and possibly a confined aquifer in the bedrock.
\end{abstract}

\section{Introduction}

Shallow landslides triggered by long-lasting, intense precipitation are a widespread natural hazard in mountain environments around the world, e.g., in Switzerland (Bezzola and Hegg, 2007, 2008; Schmid et al., 2004). Typically, the soil-bedrock interface is a characteristic failure zone, providing a slip surface at less than $2 \mathrm{~m}$ depth (Springman et al., 2012). A prominent trigger of shallow landslides in steep terrain soils is heavy rainfall, which typically leads to quick increases of positive pore water pressure and thus potentially to slope failure (Van Asch et al., 1999; Iverson, 2000; Lambe and Whitman, 1979). In order to understand the hydrological controls on landslides, knowledge about the runoff formation mechanisms is crucial. In hillslope hydrology research, subsurface stormflow (SSF) is considered to be the dominant runoff formation process in steep terrain (Weiler et al., 2006), but it is often not clear where - in which soil horizon(s) and at which depth - this flow occurs. In humid climates with steep catchments, SSF specifically affects the hydrological regime, the transport of solutes and nutrients, as well as the slope stability (Anderson et al., 2009). SSF comprises preferential infiltration into the soil, subsurface flow accumulation, and preferential lateral drainage in the soil. Accordingly, SSF can develop along (1) soil pipes in the unsaturated zone (Mosley, 1979; Zuidema, 1985), (2) soil pipes in the saturated zone due to transient groundwater rise (Uchida et al., 2002, 2005), (3) along preferential flow structures in the soil matrix in the saturated zone (Rohde, 1987; Sklash et al., 1986), or at (4) the soil-bedrock interface (Brammer and McDonnell, 1996; Tromp-van Meerveld 
and McDonnell, 2006). Other studies highlight the important role of the underlying bedrock, which can significantly contribute to runoff formation in steep terrain (Haught and Tromp-van Meerveld, 2011; Onda et al., 2001; Uchida et al., 2002, 2005). Accordingly, it is important to understand to which extent the bedrock is connected to soil structures and the soil matrix, especially for predicting pore water pressure development in slopes, e.g., for predicting shallow landslides (Tromp-van Meerveld and Weiler, 2008).

Dye tracer experiments are used to qualitatively and quantitatively determine the interactions between soil structures and the soil matrix. Brilliant blue dye experiments are typically conducted to identify soil structures that influence or enhance infiltration processes at the plot scale in rather flat terrain (Bachmair et al., 2009; Flury et al., 1994; Forrer et al., 2000; Weiler, 2001). Weiler and Flühler (2004) studied preferential infiltration with brilliant blue and focused on macropore flow initiation at four grassland sites under dry and wet antecedent soil moisture conditions. Bachmair et al. (2009) studied the control of land use and related soil structures on preferential infiltration. Anderson et al. (2009) used brilliant blue to stain a lateral preferential flow network, and focused on how preferential flow structures connect hydrologically at the hillslope scale.

The goal of the current study was to identify the dominant runoff formation mechanism(s), the dominant flowpath(s), and infiltration/exfiltration barriers together with the related soil structures in all soil horizons at a steep hillslope prone to slide. In the context of shallow landslides, the interplay between "drainability" (lateral-directional water permeability) and vertical hydraulic connectivity of different soil layers in other words how well or poorly the different soil layers drain laterally and vertically - may control the initiation of landslides. Therefore, the key objective was to identify the soil horizon(s) in which (i) infiltration/percolation accumulates and (ii) turns into lateral flow. These two key features do not necessarily appear in the same soil layer. Important research questions are:

1. Which preferential flowpaths does infiltrating rainfall take on its way into the soil?

2. How deep does rainfall water infiltrate and percolate vertically before it moves laterally (parallel to the slope's gradient)?

3. To which extent do total rainfall amount and different rainfall intensities impact runoff formation processes?

4. How much discharge $\left(\mathrm{mm} \mathrm{h}^{-1}\right)$ can different soil horizons drain under unsaturated or saturated conditions?

We conducted sprinkling experiments with artificial tracers to study runoff formation processes and to identify possible dependencies on antecedent soil moisture and precipitation intensities. Subsequently, a destructive brilliant blue dye tracer experiment was conducted to verify the findings of the sprinkling experiments and to identify and locate preferential flowpaths. These experiments aimed to determine whether preferential infiltration of precipitation leads to (i) percolation excess and lateral saturated drainage (Type A: perched aquifer) and/or (ii) rising groundwater levels along macroporous soil structures (Type B: transmissivity feedback) into higher permeable soil layers, and (iii) if these processes can induce quick pore water pressure rises and thus trigger shallow landslides in molasse formations of humid mountain regions.

\section{Materials and methods}

\subsection{Test site}

The test site Rufiberg - which means "sliding hill" in SwissGerman - is located near Lake Zug in central Switzerland $\left(1180 \mathrm{~m}\right.$ a.s.l., Lat $47.085^{\circ} \mathrm{N}$, Lon $\left.8.551^{\circ} \mathrm{E}\right)$. This area was selected due to its geologic settings and a prominent history of shallow landslides. In August 2005 a large storm event with $190 \mathrm{~mm}$ precipitation in $48 \mathrm{~h}$ triggered a suite of shallow landslides at the steep slopes of the Rufiberg (Bezzola and Hegg, 2005, 2007, 2008). The geologic and climatic settings are typical for the northern Swiss Prealps. The regional climate is humid with an annual precipitation of $1500+\mathrm{mm}$, of which about $30 \%$ falls as snow. A mosaic of mountainous conifer forests, meadows, and pasture dominates the vegetation. As such, land use is limited to forestry and dairy farming, forming the characteristic landscape of molasse zones of the Northern Alps. The Rufiberg test site is situated on a 15 to $30^{\circ}$-steep WNW-facing hillslope meadow at the initiation point of an old landslide. A suite of discharge, groundwater, and soil moisture sensors were installed in summer 2010 and experiments were performed in summer and fall 2011 (Fig. 1). The test site is a zero-order pasture catchment. Consequently, the hillslope has no continuous discharge or springs. A gleysol (H-Go-Gr) of 1.0 to $1.6 \mathrm{~m}$ depth with a prominent organic $\mathrm{H}$ horizon overlies weathered marlstone and conglomerate formations of the subalpine molasse. Soil properties of the Rufiberg gleysol are given in Table 1. For further information on the pedology and geology see Brönnimann et al. (2013).

\subsection{Instrumentation}

\subsubsection{Soil moisture}

In summer 2010, time domain reflectometry sensors (TDR; Topp et al., 1980) were installed to measure the volumetric water content (VWC) of the soil in depths of $0.25,0.7,1.1$, and $1.5 \mathrm{~m}$ in four soil pits at the Rufiberg test site (Fig. 1). The $15 \mathrm{~cm}$-long TDR rods were inserted horizontally into the undisturbed soil to the right and left of the soil pits (thus two sensors at each depth per soil pit), which were carefully refilled with the excavated soil material after TDR installation. 


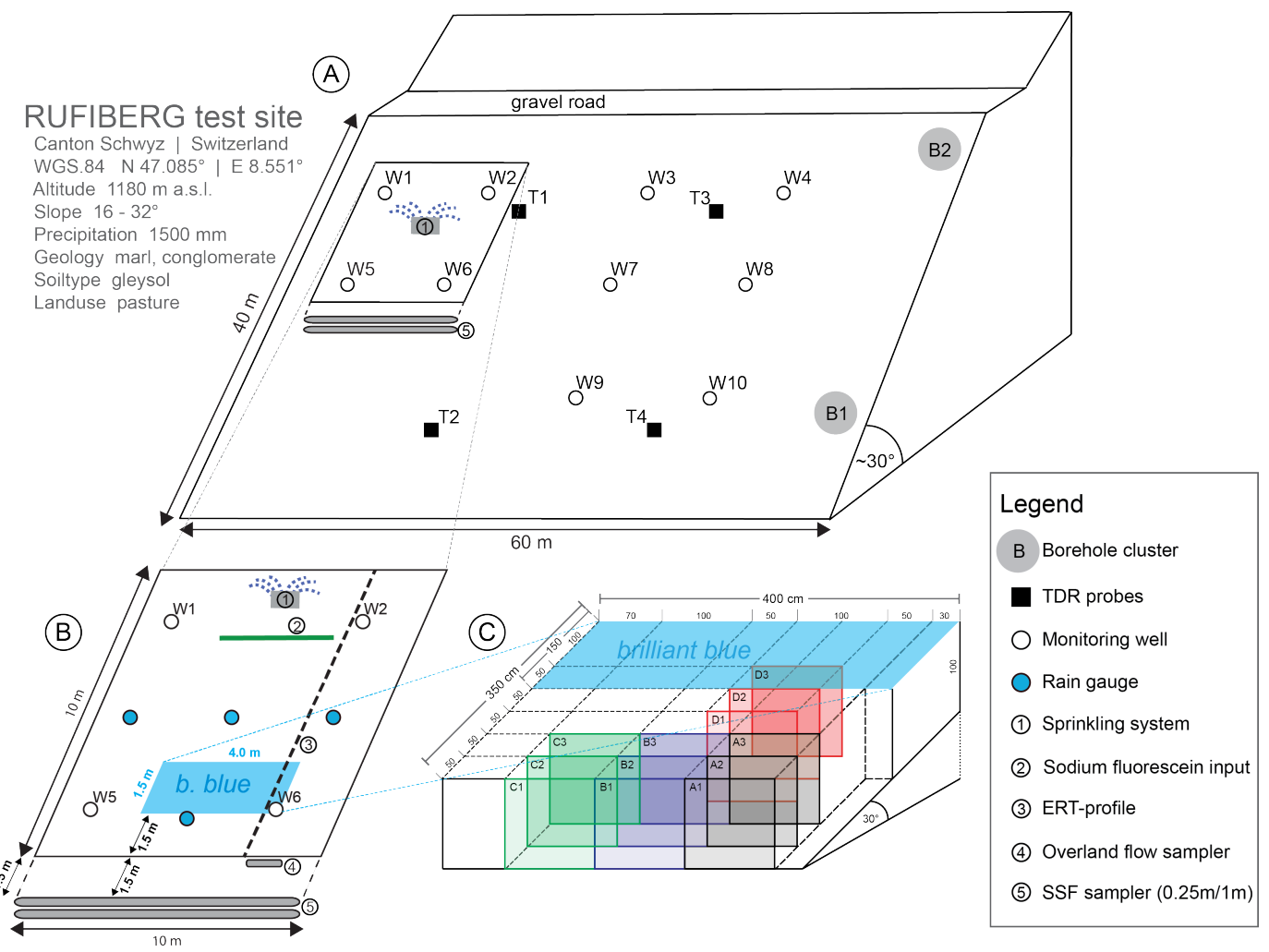

Fig. 1. Instrumentation of the Rufiberg test site. (A) $40 \mathrm{~m} \times 60 \mathrm{~m}$ experimental plot with groundwater monitoring wells W1-W10 (fully filtered from 0.05 to $1.0 / 1.45 \mathrm{~m}$ depth), TDR probe nests T1-T4 with sensors at $0.25,0.7,1.1$, and $1.5 \mathrm{~m}$ depth, and the borehole clusters B1 and B2 with three partially filtered boreholes per cluster drilled into the bedrock (Brönnimann et al., 2013). (B) $10 \mathrm{~m} \times 10 \mathrm{~m}$ sprinkling plot with temporary rain gauges installed for two sprinkling experiments. (C) $1.5 \mathrm{~m} \times 4 \mathrm{~m}$ brilliant blue dye application plot and the excavated frontal $1 \mathrm{~m} \times 1 \mathrm{~m}$ dye profiles A1-A3, B1-B3, C1-C3 and D1-D3. For the location of the lateral dye-stained profiles please see Fig. 2.

Table 1. Soil properties measured on samples from the Rufiberg's hillslope at different depths (Maries, 2011).

\begin{tabular}{lcccccc}
\hline $\begin{array}{l}\text { Depth } \\
{[\mathrm{m}]}\end{array}$ & $\begin{array}{c}\text { Sand } \\
\text { and } \\
\text { gravel } \\
{[\%]}\end{array}$ & $\begin{array}{c}\text { Silt } \\
{[\%]}\end{array}$ & $\begin{array}{c}\text { Clay } \\
{[\%]}\end{array}$ & $\begin{array}{c}\text { Plasticity } \\
\text { index } \\
{[\%]}\end{array}$ & $\begin{array}{c}\text { Total } \\
\text { porosity } \\
{[\%]}\end{array}$ & $\begin{array}{c}\text { Hydraulic } \\
\text { conductivity } \\
k_{\text {sat }} \\
{\left[\mathrm{m} \mathrm{s}^{-1}\right]}\end{array}$ \\
\hline $0.07-0.16$ & 38 & 42 & 20 & $*$ & 36 & $*$ \\
$0.24-0.38$ & 18 & 74 & 8 & 15 & 36 & $1.5 \times 10^{-10}$ \\
$0.64-0.78$ & 14 & 61 & 25 & 21 & 31 & $2.2 \times 10^{-10}$ \\
$1.04-1.18$ & 2 & 63 & 35 & 26 & 39 & $1.9 \times 10^{-10}$ \\
$1.52-1.66$ & 0 & 66 & 34 & 23 & 36 & $6.6 \times 10^{-10}$ \\
\hline
\end{tabular}

* Plasticity index and hydraulic conductivity $k_{\text {sat }}$ in the topmost layer $(0.07-0.16 \mathrm{~m}$ depth) could not be determined as the quality of the topsoil sample - specifically in terms of root holes and organic content - made it impossible to produce meaningful data.

From June 2010 to November 2011 VWC was recorded with a Campbell TDR 100 system in time steps of $10 \mathrm{~min}$ (Brönnimann et al., 2013).

\subsubsection{Groundwater}

From June 2010 to November 2011 we measured groundwater levels in the soil at 10 fully filtered wells (2" HDPE pipes with $0.3 \mathrm{~mm}$ slot width from Ejikelkamp/NL) at depths ranging from 1.2 to $1.5 \mathrm{~m}$ in $10 \mathrm{~min}$ time intervals with capacitance rod water level loggers (Odyssey/NZ). The monitoring wells were equally distributed over the test site, four of them being within the $10 \mathrm{~m} \times 10 \mathrm{~m}$ sprinkling area (Fig. 1). Additionally, six boreholes were drilled in two clusters reaching depths between 2 and $9 \mathrm{~m}$ below the surface to monitor deep groundwater dynamics in the bedrock with DCX22 pressure sensor-logger units from Keller, Winterthur/CH (Fig. 1, Brönnimann et al., 2013). The borehole clusters allow for direct measurement of the hydraulic pressure of the low permeable bedrock lithology.

\subsubsection{Discharge}

Overland and near-surface flow was recorded during the sprinkling experiments in summer and fall 2011 using a $1.0 \mathrm{~m}$-wide surface flow collector (stainless steel with a PVC "rain hood", customized design), which was installed in the 
Table 2. Summary of the total precipitation, total flow, and total applied tracer masses (fluorescein: line tracer injection in topsoil; $\mathrm{NaCl}$ : applied into sprinkling water) in the first sprinkling experiment (3 August 2011) and second sprinkling experiment (6 October 2011).

\begin{tabular}{llcclcccc}
\hline & $\begin{array}{l}\text { Total } \\
\text { precipitation } \\
{[\mathrm{L}]}\end{array}$ & $\begin{array}{r}\text { Total } \\
\mathrm{SOF}^{1} \\
{[\mathrm{~L}]}\end{array}$ & $\begin{array}{c}\text { Total } \\
\mathrm{SSF}_{0.25 \mathrm{~m}}^{2} \\
{[\mathrm{~L}]}\end{array}$ & $\begin{array}{l}\text { Total } \\
\mathrm{SSF}_{1.0 \mathrm{~m}}^{2}\end{array}$ & $\begin{array}{c}\text { Applied } \\
\text { fluorescein } \\
{[\mathrm{g}]}\end{array}$ & $\begin{array}{c}\text { Recovery } \\
\text { fluorescein } \\
{[\mathrm{g}]}\end{array}$ & $\begin{array}{c}\text { Applied } \\
\mathrm{NaCl} \\
{[\mathrm{kg}]}\end{array}$ & $\begin{array}{l}\text { Recovery } \\
\mathrm{NaCl} \\
{[\mathrm{kg}]}\end{array}$ \\
\hline first Exp. & $7420^{3}$ & 100 & 360 & $700^{4}$ & 10 & 0.045 & 5 & 1.3 \\
second Exp. & 8300 & 1800 & 630 & 640 & 10 & 0.045 & 3 & 2.65 \\
\hline
\end{tabular}

${ }^{1}$ Saturation overland flow (SOF) was collected in a $1.0 \mathrm{~m}$-wide sampler, thus total SOF flow volumes were multiplied by a factor of $10 .{ }^{2}$ Subsurface stormflow (SSF) was collected in $10 \mathrm{~m}$-long drainage pipes at 0.25 and $1.0 \mathrm{~m}$ depth. ${ }^{3}$ Total precipitation $=$ artificial + natural precipitation $=6500 \mathrm{~L}+(220+700) \mathrm{L}=7420 \mathrm{~L}$ on the $10 \mathrm{~m} \times 10 \mathrm{~m}$ irrigation plot; this equals $65 \mathrm{~mm}$ artificial rainfall plus $2.2 \mathrm{~mm}$ natural rainfall during and $7 \mathrm{~mm}$ shortly before irrigation. ${ }^{4}$ In the first experiment, the $1.0 \mathrm{~m}$-deep drainage pipe continued to run for several hours after the end of the sprinkling. For comparing both experiments, we calculated the total values for a $6 \mathrm{~h}$ interval starting at the onset of the sprinkling.

topsoil in a depth of $0.05 \mathrm{~m}$ next to the $10 \mathrm{~m} \times 10 \mathrm{~m}$ irrigation field (Fig. 1b). From August 2010 to October 2011 subsurface stormflow (SSF) was monitored at 0.25 and $1.0 \mathrm{~m}$ depth $1.5 \mathrm{~m}$ downslope of the irrigation field (Fig. 1). SSF was collected in two $10 \mathrm{~m}$-long drainage pipes (PVC, $100 \mathrm{~mm}$ outer diameter, $2 \mathrm{~mm}$ slot width with $5 \mathrm{~mm}$ spacing on the upper half of the pipe) and measured with two large side-tipping buckets (customized design) connected to a magnetic counter and a Campbell CR1000 logger.

\subsubsection{Field experiments}

Additional sensors and equipment were installed for the sprinkling experiments conducted in August and October 2011. As there are neither springs nor continuous running streams at the Rufiberg, we used a truck with a $10000 \mathrm{~L}$ water tank filled with water from nearby Lake Zug for the sprinkling experiments. We monitored the water level in 5 min time steps in the water tank with a pressure transducer (STS DL/N 70, Sensortechnik Sirnach/CH) and the cumulated water flux in $30 \mathrm{~min}$ time steps in the hose system feeding the sprinklers with a calibrated flow-meter (measurement range from 10 to $120 \mathrm{~L} \mathrm{~min}^{-1}$ from Piusi, Suzzara/IT). In parallel, we installed four precipitation totalisators at the $10 \mathrm{~m} \times 10 \mathrm{~m}$ irrigation plot for monitoring onsite rainfall intensity and total rainfall as well as its spatial distribution over the plot. The sprinkling water was pumped from the $10000 \mathrm{~L}$ water tank with a double-acting pump (Gardena 4000/5, Ulm/DE) in 3/4-inch hoses towards the three sprinkler units (Gardena Comfort Aquazoom 350/2, Ulm/DE). Runoff into the surface flow collector was sampled manually with a bucket, whereas the discharge at 0.25 and $1.0 \mathrm{~m}$ depth was sampled with automated water samplers for lab analysis (Teledyne-ISCO 2900, USA) and monitored online in two flow-through sensor cells (acryl, custom design) in $2 \mathrm{~s}$ time steps for fluorescein with two fluorometers (Albilia GGUN-FL 30, Neuchatel/CH), and in $10 \mathrm{~s}$ time steps for $\mathrm{NaCl}$ with two conductometers (WTW Multi 3420, Weilheim/DE).

\subsection{Sprinkling experiments}

We conducted two sprinkling experiments on the $10 \mathrm{~m} \times 10 \mathrm{~m}$ plot at the Rufiberg test site in summer 2011. The water reservoir $(10000 \mathrm{~L})$ limited the possible total irrigation to approximately $100 \mathrm{~mm}$ per day at the $10 \mathrm{~m} \times 10 \mathrm{~m}$ sprinkling site; this is comparable to the rainfall intensities of the August 2005 storm event $(190 \mathrm{~mm}$ $48 \mathrm{~h}^{-1}$, return period $100 \mathrm{yr}$; Bezzola and Hegg, 2008). The experimental sprinkling equipment had a maximum irrigation intensity of $25 \mathrm{~mm} \mathrm{~h}^{-1}$, which matches rainfall intensities for the Rufiberg with a return period of $2.33 \mathrm{yr}$ for the $1 \mathrm{~h}$ maximum rainfall intensity (Geiger et al., 1992; Jensen et al., 1997). The design for the first sprinkling experiment on 3 August 2011 was to irrigate with a rainfall intensity of $20 \mathrm{~mm} \mathrm{~h}^{-1}$ for $2 \mathrm{hr}$, followed by $1 \mathrm{hr}$ with an increased intensity of $25 \mathrm{~mm} \mathrm{~h}^{-1}$ (total artificial rainfall $65 \mathrm{~mm}$ in $3 \mathrm{~h}$, Table 2). The design for the second sprinkling experiment on 6 October 2011 was to start with a rainfall intensity of $25 \mathrm{~mm} \mathrm{~h}^{-1}$ for $1 \mathrm{hr}$, followed by $3 \mathrm{hr}$ with an intensity of $20 \mathrm{~mm} \mathrm{~h}^{-1}$ (total artificial rainfall $83 \mathrm{~mm}$ in $4 \mathrm{~h}$, Table 2). In the first sprinkling experiment $7 \mathrm{~mm}$ of natural rainfall occurred in the hours before the onset of the sprinkling and $2.2 \mathrm{~mm}$ during the sprinkling (total rainfall $=65 \mathrm{~mm}+9.2 \mathrm{~mm}=74.2 \mathrm{~mm}$, Table 2). This $7 \mathrm{~mm}$ natural rainfall did not produce runoff, but partly contributed to higher antecedent soil moisture values for the first sprinkling experiment (Brönnimann et al., 2013). Before and during the second sprinkling experiment no natural rainfall occurred.

The applied total rainfall amounts in the sprinkling experiments were 74.2 and $83 \mathrm{~mm}$, respectively, which both exceed the $24 \mathrm{~h}$ total rainfall with a return period of $2.33 \mathrm{yr}(70 \mathrm{~mm})$. However, if the return periods for total artificial rainfall are determined relative to the sprinkling duration $(65 \mathrm{~mm}$ in $3 \mathrm{~h}$ for the first and $83 \mathrm{~mm}$ in $4 \mathrm{~h}$ for the second experiment) both return periods are on the order of $20 \mathrm{yr}$ (Geiger et al., 1992; Jensen et al., 1997). However, all these return periods are not based on a precipitation time series at the Rufiberg. Instead the nearest Meteoswiss rain gauge at Zugerberg $(6.5 \mathrm{~km} \mathrm{~N}$ of 
the Rufiberg, data record starts in 1910) is the basis for the return period calculations, thus an uncertainty factor of 1.5 for $24 \mathrm{~h}$ total rainfall should be considered (Jensen et al., 1997).

To estimate flow velocities in the soil during both sprinkling experiments, the tracers fluorescein $(10 \mathrm{~g}$ fluorescein diluted in $5 \mathrm{~L}$ water, line tracer application $0.05 \mathrm{~m}$ below the soil surface before the onset of sprinkling; Fig. $1 \mathrm{~b}$ and Table 2) and $\mathrm{NaCl}$ were applied (first experiment $5 \mathrm{~kg} \mathrm{NaCl}$, second experiment $3 \mathrm{~kg} \mathrm{NaCl}$; added to an additional $100 \mathrm{~L}$ sprinkling water tank at the time, when the sprinkling rate was changed; Figs. 4, 5 and Table 2).

\subsection{Dye tracer experiment}

In November 2011, we performed a final, destructive sprinkling experiment with a dye tracer solution (Brilliant Blue $F C F$, C.I. $42090,6.25 \mathrm{~g} \mathrm{~L}^{-1} \mathrm{H}_{2} \mathrm{O}$ ) with an irrigation rate of $20 \mathrm{~mm} \mathrm{~h}^{-1}$ and a total irrigation of $40 \mathrm{~mm}$ (total dye tracer volume $240 \mathrm{~L}$ ). The sprinkling area of $1.5 \times 4 \mathrm{~m}$ was located in the lower section of the $10 \mathrm{~m} \times 10 \mathrm{~m}$ irrigation field (Fig. 1). We sprinkled the dye solution until the lower drainage pipe at $1.0 \mathrm{~m}$ depth started to produce runoff, which occurred after $2 \mathrm{~h}$. The day after the dye sprinkling, we started to excavate the stained soil beginning from the drainage pipes (approx. $3 \mathrm{~m}$ downslope of the dye sprinkling), which resulted in nine lateral and twelve frontal $1 \mathrm{~m} \times 1 \mathrm{~m}$ stained soil profiles after 4 days of consecutive excavation (Fig. 2, we started with the profiles A1, B1, C1 followed by the next series of profiles A2, B2, B3 etc.). The stained soil profiles were excavated and subsequently photographed with a high-resolution digital camera in blocks of two to three layers with a spacing of $0.5 \mathrm{~m}$ to identify the 3-D structure of the dye-stained subsurface flowpaths (Fig. 2). The pictures of the soil profiles were taken with a digital camera (Panasonic Lumix GH2 with a $28 \mathrm{~mm}$ fixfocal length lens, automatic white balance, ISO 160-800 and a skylight filter) under daylight condition beneath a tarp to diffuse the light and avoid direct sunlight and shadow effects. For the analysis of similarities and differences in the vertical dye patterns in the 21 profile pictures, the pictures were evaluated digitally using methods developed by Weiler and Flühler (2004). The analysis consisted of the following steps (Fig. 3):

1. Optical distortion and rectification correction.

2. Color adjustment and conversion from Red-GreenBlue values (RGB) into the Hue-Saturation-Value color space (HSV) using a gray scale as a reference. We selected $18 \%$ gray as the brightest patch $(=256)$ and the darkest patch as black $(=0)$ to compensate for different light conditions.

3. Classification of dye-stained areas in the HSV color space by a robust, semi-supervised classification technique (Weiler and Flühler, 2004).
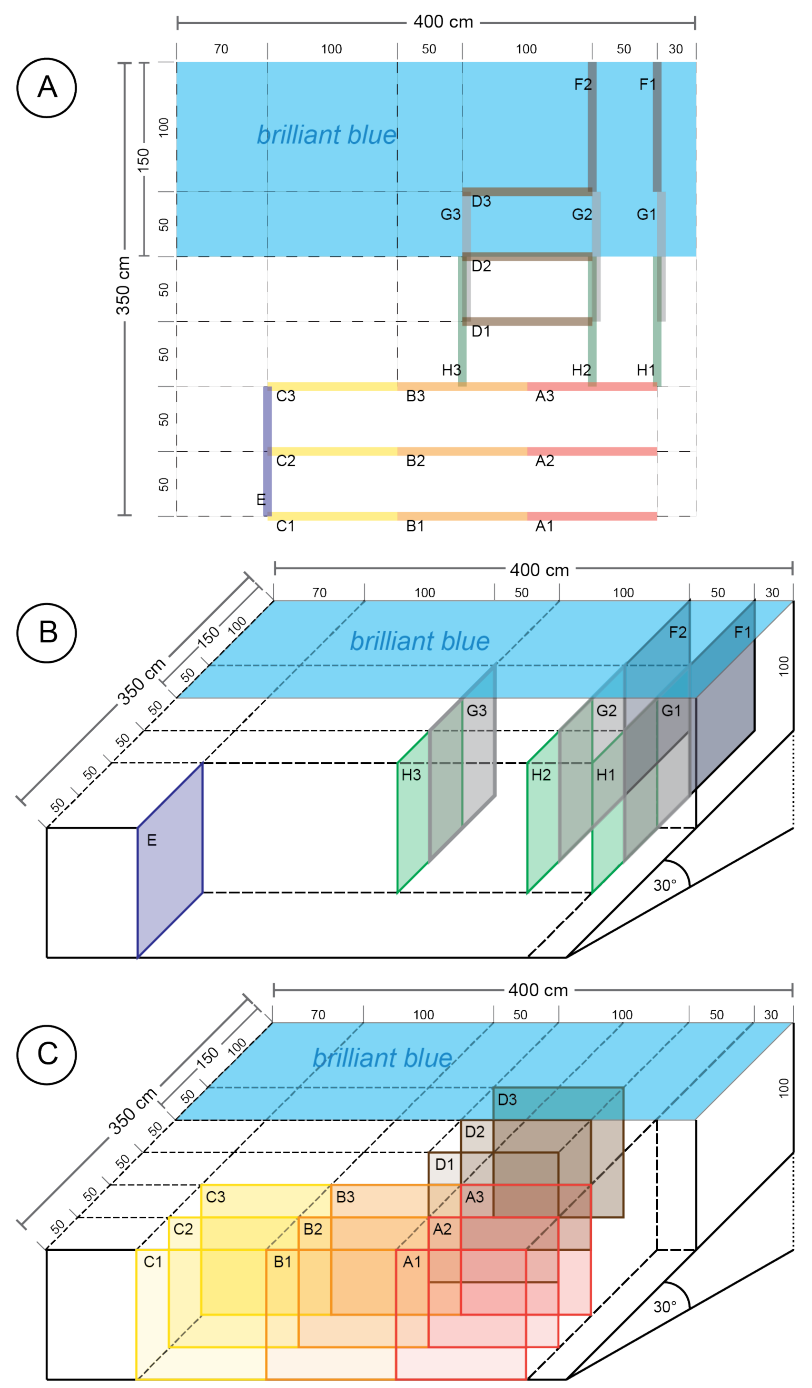

Fig. 2. Dye tracer experiment overview. (A) 2-D top view of the $1.5 \mathrm{~m} \times 4 \mathrm{~m}$ brilliant blue dye application plot with $1 \mathrm{~m} \times 1 \mathrm{~m}$ profiles excavated on 2-5 November 2011. (B) 3-D diagram of the $1 \mathrm{~m} \times 1 \mathrm{~m}$ lateral (=parallel to slope's gradient) dye-stained profiles E, H1-H3, G1-G3 and F1-F2. (C) 3-D diagram of the $1 \mathrm{~m} \times 1 \mathrm{~m}$ frontal (= perpendicular to slope's gradient) dye-stained profiles A1-A3, B1-B3, C1-C3 and D1-D3.

4. Manual digitalization of the terrain surface, grass and large stones.

5. Application of a conditional dilation algorithm to improve the classification of dye-stained soil structures by reducing noise such as single stained pixels in unstained zones or un-stained pixels in stained zones (Serra, 1988). The conditional dilation uses dilate and erode functions to homogenize dye patterns by integrating single dye pixels into neighboring larger dye patterns. "The conditional dilation algorithm results in images with a higher spatial coherence and a lower interference of noise" (Weiler, 2001). 

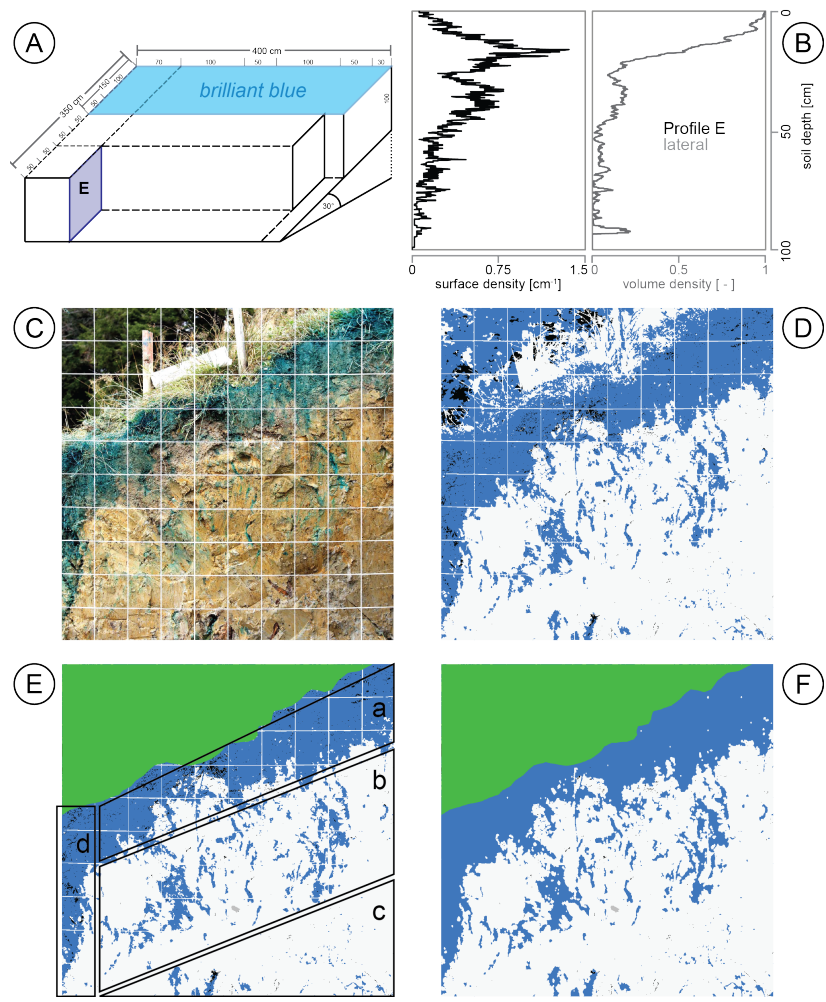

Fig. 3. Steps of the image analysis for the dye brilliant blue. (A) Location of the lateral (= parallel to the slope's gradient) $1 \mathrm{~m} \times 1 \mathrm{~m}$ soil profile E with dye-stained soil structures. (B) The parameters surface density and volume density are derived by the image analysis with the following steps: (C) optical distortion and rectification correction, (D) dye color identification based on algorithms developed by Weiler and Flühler (2004), (E) digitalization of terrain surface (soil, vegetation, atmosphere) and large stones (gray shapes), and (F) application of a conditional dilation algorithm to improve the dye-stained soil structures (e.g., removes the grid). (E) shows the dye staining patterns in relation to the soil horizons and structures of the gleysol: (a) organic H horizon (0 to $0.1 / 0.2 \mathrm{~m}$ ) with dye-stained matrix, (b) Go horizon $(0.1 / 0.2$ to $0.5 / 0.6 \mathrm{~m})$ with stained macropores (worm burrows), (c) Gr horizon (0.5/0.6 to $1.0 \mathrm{~m}$ ) with few dye-stained structures, where the dye-stained area reaches a minimum; exceptions were due to dead tree roots and (d) a stained soil fracture perpendicular to the slope's gradient.

These steps resulted in 21 binary pictures of approximately $1000 \times 1000$ pixels classified into stained or unstained soil showing the dye tracer patterns for the different vertical $1 \mathrm{~m} \times 1 \mathrm{~m}$ soil profiles. These binary pictures were further evaluated by computing the fraction of stained pixels per depth below ground surface (volume density). The parameter volume density does not provide information about size, form and structure of the stained objects, it is limited - and thus a synonym - to the term dye coverage per depth (Bogner et al., 2013; Flury et al., 1994; Forrer et al., 2000). To classify the dimension of stained objects in the soil we calculated the stained path width for each soil depth expressed in the parameter surface density. Surface density is the surface area (2-D) of a stained structure divided by the volume of the 3 -D reference space, which is estimated from the intercept density calculated from the number of intercepts between stained and unstained pixels per depth (Weiler and Flühler, 2004). The parameter surface density originates from established methods of stereology (Weibel, 1979) and can be applied to a suite of 2-D stained soil profiles "slices" of a 3-D soil block by delineating a 3-D parameter based on 2-D measurements. High values of surface density indicate a large number of small features, low values represent few but larger stained objects (Weiler, 2001). If surface density is nearly zero, either no feature is stained or a dominant feature covers the entire depth. In such an ambivalent case, volume density is needed to differentiate between these two possibilities.

\section{Results}

\subsection{Sprinkling experiments}

\subsubsection{Soil moisture response}

The volumetric water content (VWC) was monitored during the sprinkling experiments using TDR nest T1, as it is next to the irrigation plot (Fig. 1a). Interestingly, only the TDR probes at 0.25 and $0.7 \mathrm{~m}$ depth showed clear reactions to the sprinkling experiments with an increase of VWC from approximately 0.40 to 0.45 at $0.7 \mathrm{~m}$ depth and an increase from 0.40 to 0.47 at $0.25 \mathrm{~m}$ depth in both experiments (Figs. 4 and 5). In contrast, the deeper TDR probes at 1.1 and $1.5 \mathrm{~m}$ depth did not show a significant reaction and continuously measured high VWC values oscillating around 0.48 at $1.1 \mathrm{~m}$ depth and 0.51 at $1.5 \mathrm{~m}$ depth, respectively (Figs. 4 and 5). In the first sprinkling experiment (Fig. 4) VWC at 0.25 and $0.7 \mathrm{~m}$ depth increased immediately after the onset of the irrigation, which we attribute to slightly wetter antecedent conditions in the topsoil compared to the second sprinkling experiment ( 0.42 and 0.41 compared to 0.39 and 0.40 at 0.25 and $0.7 \mathrm{~m}$ depth, respectively). In the second sprinkling experiment starting with the higher initial irrigation rate, VWC started to rise in the two upper TDRs approximately $30 \mathrm{~min}$ after the onset of the irrigation (Fig. 5).

\subsubsection{Groundwater response}

Starting from different levels, all the groundwater wells exhibited strong groundwater level rises during both sprinkling experiments reaching near-surface values - most prominently in well W2 and W5 (Figs. 4 and 5). In the first sprinkling experiment, groundwater levels in well W2 increased rapidly shortly after VWC increased in the topmost TDR nests, and reached nearly the terrain surface within less than 90 min of irrigation onset, whereas W1 and W5 exhibited much slower groundwater level rises peaking much later (Fig. 4). The drier antecedent conditions are expressed by 

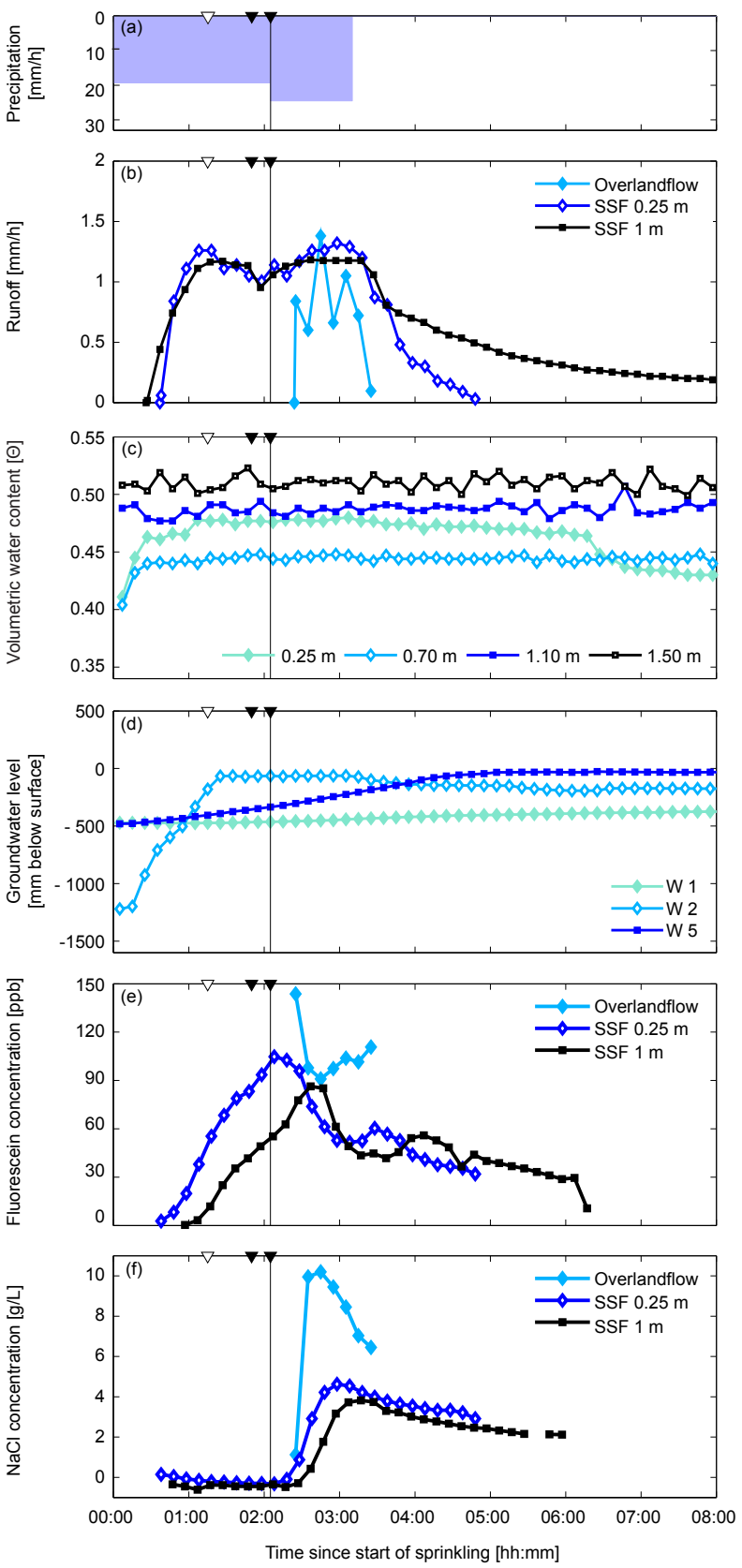

Fig. 4. First sprinkling experiment on 3 August 2011 at the Rufiberg's $10 \mathrm{~m} \times 10 \mathrm{~m}$ plot (Fig. 1). (a) Precipitation (total artificial rainfall $65 \mathrm{~mm}+2.2 \mathrm{~mm}$ natural rainfall; $7 \mathrm{~mm}$ natural rainfall occurred in the hours before the sprinkling). (b) Runoff in surface flow collector and subsurface drainage at $0.05,0.25$ and $1.0 \mathrm{~m}$ depth (Fig. 1). (c) Volumetric water content measured at TDR nest T1. (d) Groundwater dynamics in monitoring wells W1, W2, and W5 (no data for W6 due to malfunctioning of sensor-logger unit). (e) Fluorescein tracer breakthrough curve and (f) $\mathrm{NaCl}$ tracer breakthrough curve in surface flow at $0.05 \mathrm{~m}$ depth, shallow subsurface flow at $0.25 \mathrm{~m}$ depth, and deep subsurface flow at $1.0 \mathrm{~m}$ depth. The white triangle represents the onset of $2.2 \mathrm{~mm}$ natural precipitation, the black triangles indicate two $5 \mathrm{~min}$ irrigation stops for sprinkler cleaning. The black line indicates a change in irrigation intensity from 20 to $25 \mathrm{~mm} \mathrm{~h}^{-1}$ and the $\mathrm{NaCl}$ tracer application.
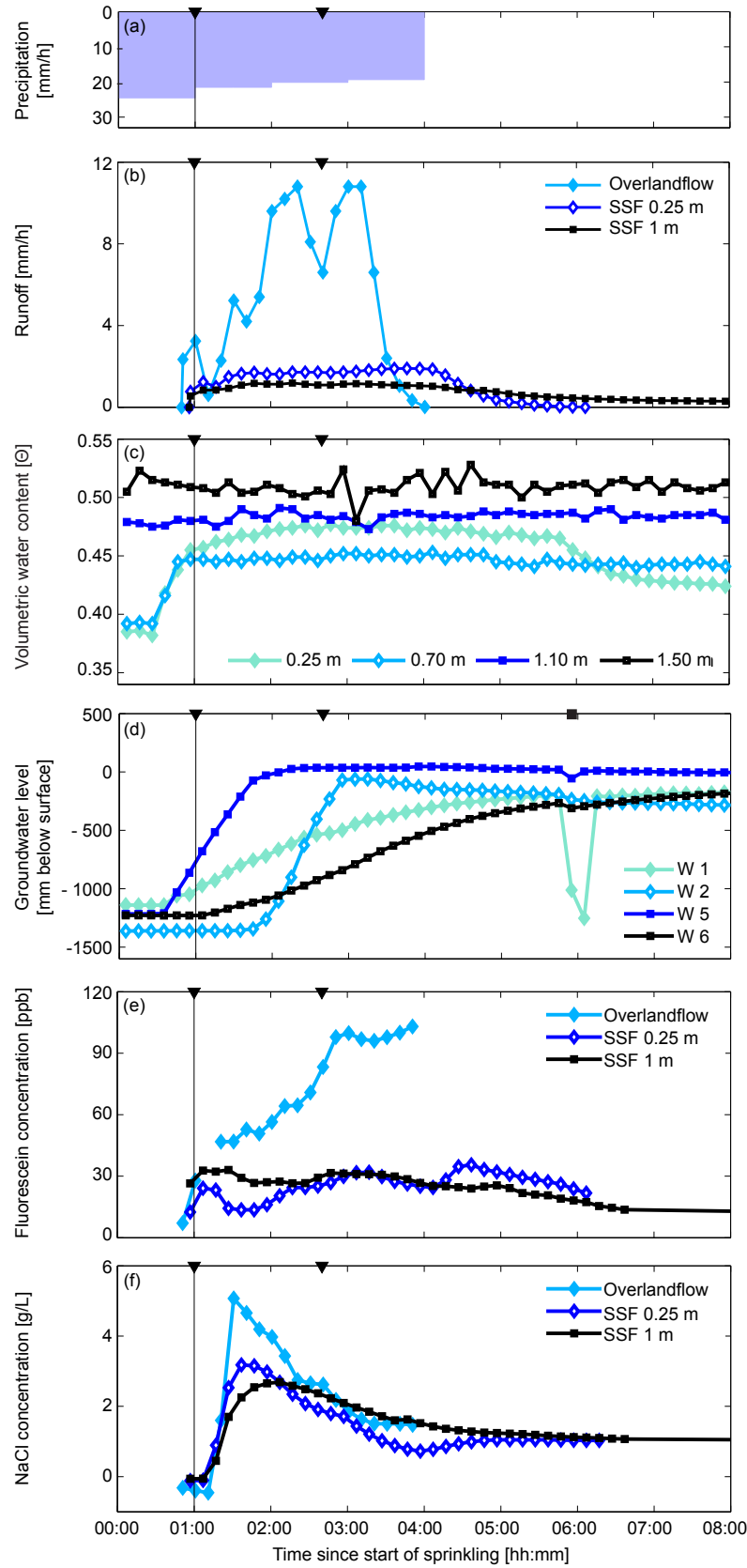

Fig. 5. Second sprinkling experiment on 6 October 2011 at the Rufiberg's $10 \mathrm{~m} \times 10 \mathrm{~m}$ plot (Fig. 1). (a) Precipitation (total artificial rainfall $83 \mathrm{~mm}$ ). (b) Runoff in surface flow collector and subsurface drainage at $0.05,0.25$ and $1.0 \mathrm{~m}$ depth (Fig. 1). (c) Volumetric water content measured at TDR nest T1. (d) Groundwater dynamics in monitoring wells W1, W2, W5, and W6. (e) Fluorescein tracer breakthrough curve and (f) $\mathrm{NaCl}$ tracer breakthrough curve in surface flow at $0.05 \mathrm{~m}$ depth, shallow subsurface flow at $0.25 \mathrm{~m}$ depth, and deep subsurface flow at $1.0 \mathrm{~m}$ depth. The black triangles indicate two 5 min irrigation stops for sprinkler cleaning. The black line indicates a change in irrigation intensity from 25 to $20 \mathrm{~mm} \mathrm{~h}^{-1}$ and the $\mathrm{NaCl}$ tracer application. GW grab samples were manually taken at all wells approx. $6 \mathrm{~h}$ after the start of the sprinkling, indicated in (d) by a black square. 
lower initial groundwater levels before the second experiment (Fig. 5).

In this second experiment (Fig. 5), W2 showed a delayed reaction to the sprinkling, whereas W5 showed almost the same pattern as $\mathrm{W} 2$ in the first experiment, reaching the terrain surface $2 \mathrm{~h}$ after the onset of the irrigation with the main difference of a delayed rise (this might be attributed to the later rise of the topsoil's VWC due to the lower initial soil moisture). Well W2 reached near-terrain levels $3 \mathrm{~h}$ after the irrigation onset, whereas W1 and W6 showed much slower groundwater rises with lower maximum groundwater levels.

\subsubsection{Discharge response}

We detected a threshold for the onset of runoff at the Rufiberg test site ranging from 9 to $21 \mathrm{~mm}$ total rainfall depending on rainfall intensity and antecedent soil moisture of the topsoil (Table 3). Rainfall intensities continuously above $20 \mathrm{~mm} \mathrm{~h}^{-1}$ for longer periods (> $20 \mathrm{~min}$; dependent on antecedent soil moisture in the $\mathrm{H}$ horizon) produced saturated overland flow (SOF) in addition to subsurface stormflow (SSF) in the $\mathrm{H}$ horizon (organic layer interflow). During the first experiment (Fig. 4), when we started with $20 \mathrm{~mm} \mathrm{~h}^{-1}$ for two hours and increased the rainfall intensity to $25 \mathrm{~mm} \mathrm{~h}^{-1}$ for the third hour of irrigation, SOF only occurred after the rainfall intensity was increased. The $1 \mathrm{~m}$-deep drainage discharged first, followed by the 0.25 m-deep drainage, and last by the surface flow collector, which produced runoff approx. $20 \mathrm{~min}$ after the rainfall intensity was increased (Fig. 4).

During the second experiment (Fig. 5), when we started with an intensity of $25 \mathrm{~mm} \mathrm{~h}^{-1}$ for an hour and continued with $20 \mathrm{~mm} \mathrm{~h}^{-1}$ for another three hours, SOF started shortly before the onset of subsurface flow and contributed significantly more to the total discharge (Table 2). In this second experiment (Fig. 5), total runoff is significantly higher - mostly due to SOF of up to $11 \mathrm{~mm} \mathrm{~h}^{-1}$ - whereas SSF in the 0.25 and $1.0 \mathrm{~m}$ drainage is limited to $1.5 \mathrm{~mm} \mathrm{~h}^{-1}$ (similar to the first experiment, Table 2). The surface flow collector discharged first, quickly (less than $5 \mathrm{~min}$ ) followed by both SSF drainages (Fig. 5). Due to the fact that surface flow only occurred after the TDRs showed significant increases of VWC at 0.25 and $0.7 \mathrm{~m}$ depths, we excluded infiltration excess hortonian overland flow (HOF) during both sprinkling experiments (Figs. 4 and 5).

\subsubsection{Tracer response}

In the first experiment (Fig. 4), fluorescein breakthrough occurs first in the $0.25 \mathrm{~m}$ SSF drainage, although an earlier onset of discharge in the $1.0 \mathrm{~m} \mathrm{SSF}$ drainage is observed. However, the highest fluorescein concentrations were measured in the $0.05 \mathrm{~m}$ surface flow collector, followed by the $0.25 \mathrm{~m}$ drainage and lowest values in the $1.0 \mathrm{~m}$ SSF drainage (Fig. 4).
In the second experiment (Fig. 5), the fluorescein breakthrough occurred nearly simultaneously for all draining depths starting at the onset of discharge, reaching highest concentrations in the surface flow collector and significantly lower values in the 0.25 and $1.0 \mathrm{~m}$ SSF drainages. The observed flow velocities for fluorescein in the soil were 1.2 and $1.4 \times 10^{-3} \mathrm{~m} \mathrm{~s}^{-1}$ for the first and the second experiment, respectively (Table 4). These velocities were consistent with observations from similar experiments at other experimental hillslopes (Table 4).

The $\mathrm{NaCl}$ breakthrough curves showed similar behavior for both experiments, with higher concentrations for the flow collectors/drainages closer to the surface (Figs. 4 and 5). This supports the theory of a "primary" subsurface drainage system (SSF) with event and pre-event water mixing, and a "secondary" event water dominated surface drainage (SOF), which is activated when precipitation reaches values above a certain intensity threshold $\left(20 \mathrm{~mm} \mathrm{~h}^{-1}\right)$ for longer periods (>20 min). Following this theory, SOF occurs either when the subsurface drainage systems (SSF type 1) are beyond their capacity or the rainfall intensity surpasses the drainage capacity of the topsoil's H horizon (SSF type 2). Both "primary" types of runoff formation fall into the category subsurface stormflow (SSF, Weiler et al., 2006):

- SSF type 1 is consistent with a transmissivity feedback of the soil, caused by vertical infiltration and percolation into deeper soil layers, resulting in a rise of the phreatic zone into soil horizons with higher lateral hydraulic conductivity (Rohde, 1987). In this case the onset of SOF occurs when the saturated hydraulic conductivity reaches the land surface (full saturation of soil profile).

- SSF type 2 is consistent with organic layer interflow, which is laterally draining the $\mathrm{H}$ horizon independently of the saturation of deeper soil layers. SSF type 2 may significantly contribute to "secondary" SOF via return flow when rainfall intensities persistently exceed a threshold of $20 \mathrm{~mm} \mathrm{~h}^{-1}$. In this case the soil profile must not be fully saturated as topsoil or subsoil air entrapment may prevail (e.g., in the second sprinkling experiment, when we started with a rainfall intensity above this threshold).

\subsection{Dye tracer experiment}

The brilliant blue dye tracer experiment contradicts the findings of the sprinkling experiments, which suggested significant lateral tracer fluxes of $\mathrm{NaCl}$ and fluorescein in the subsoil G horizons (Figs. 4 and 5). Both SSF drainage pipes in 0.25 and $1.0 \mathrm{~m}$ depths reacted rather quickly to the onset of both sprinkling experiments. With the dye tracer experiment we were explicitly looking where vertical percolation starts to discharge laterally via macropore flow systems in all soil horizons (research question). We excavated soil 
Table 3. Precipitation threshold for runoff generation at different experimental hillslopes.

\begin{tabular}{lcl}
\hline Study site & $\begin{array}{c}\text { Precipitation } \\
\text { threshold } \\
{[\mathrm{mm}]}\end{array}$ & Reference \\
\hline Rufiberg (Switzerland) & $9-21$ & This article \\
Rufiberg (Switzerland) & 17 & Brönnimann et al. (2013) \\
Maimai (New Zealand) & 18 & Mosley (1979); McGlynn et al. (2002) \\
Maimai (New Zealand) & $17-23$ & Graham et al. (2010) \\
Jozankei (Japan) & $10-20$ & Uchida et al. (2005) \\
Toinotani (Japan) & 35 & Uchida et al. (2005) \\
Hecla Greens Creek (USA) & 10 & Hopp et al. (2011) \\
Panola Mountain (USA) & 55 & Tromp-van Meerfeld and McDonnell (2006) \\
\hline
\end{tabular}

Table 4. Dominant lateral effective velocity ( $\left.v_{\text {eff }}\right)$ for subsurface storm flow (SSF) at different experimental hillslopes.

\begin{tabular}{llll}
\hline Soil type/catchment & Tracer & $v_{\text {eff }}\left[\mathrm{m} \mathrm{s}^{-1}\right]$ & Reference \\
\hline Gleysol, Rufiberg, CH (first experiment) & Fluorescein & $1.2 \times 10^{-3}$ & This article \\
Gleysol, Rufiberg, CH (second experiment) & Fluorescein & $1.4 \times 10^{-3}$ & This article \\
Gleysol, Heumös hillslope, & Fluorescein, & $1.0 \times 10^{-3}$ to & Wienhöfer et al. (2009) \\
Vorarlberg, A & Sodium chloride & $2.0 \times 10^{-2}$ & \\
Gleysol, Vogelbach, & Fluorescein, & $4.5 \times 10^{-3}$ to & Weiler et al. (1998) \\
Alptal, CH & Sodium bromide & $4.0 \times 10^{-2}$ & \\
Organic- and clay-rich soils, & Sodium chloride & $2.8 \times 10^{-5}$ to & Anderson et al. (2009) \\
Russell Creek catchment, BC, Canada & & $9.2 \times 10^{-2}$ & \\
Organic-rich sandy colluvium, & Sodium bromide, & $4.0 \times 10^{-3}$ to & Anderson et al. (1997) \\
CB1 catchment, Oregon, USA & Deuterium & $6.0 \times 10^{-3}$ & \\
Podzolized yellow-brown earths, & Bromide & $1.8 \times 10^{-3}$ to & Graham et al. (2010) \\
Maimai hillslope, NZ & & $1.2 \times 10^{-2}$ & \\
Artificial waste rock cover, & Amino G acid (AGA), & $1.2 \times 10^{-3}$ & Hopp et al. (2011) \\
(4 drainage and compacted layers) & monopotassium salt & & \\
Hecla Greens Creek, Alaska, USA & & & \\
\hline
\end{tabular}

profiles starting at the drainage pipes (Fig. 2) over their entire width of $10 \mathrm{~m}$ down to a depth of $1.3 \mathrm{~m}$ to identify any lateral preferential or matrix flow connected to the drainages. Based on the dye staining of the soil (Figs. 6 and 7) we identified only a single significant lateral preferential flow system - in the organic topsoil (H horizon). We observed a form of shallow subsurface stormflow (SSF) described by Weiler and McDonnell (2004) as organic layer interflow. In contrast to the interpretation of the sprinkling experiment data, no dye-stained lateral features and thus no lateral preferential or matrix flow were observed in the subsoil (Go and $\mathrm{Gr}$ horizon). The dye tracer data support organic layer interflow (SSF type 2) as the "primary" runoff formation process at the Rufiberg.

\subsubsection{General dye patterns}

The profiles showed obvious patterns with area-wide stained regions in the upper $0.2 \mathrm{~m}$ of the soil profile and less stained horizons further down. Most of the profiles are located outside of the dye application area (downslope in flow direction, Fig. 2). The lateral and frontal profiles showed comparable patterns and the vertical distribution of dye-stained soil was relatively similar for all profiles near to the dye application area (Fig. 7). The dye distribution in the topsoil impaired the dye patterns in the deeper horizons. Areas below stained topsoil typically showed a higher fraction of staining than areas with a reduced or absent topsoil staining (Fig. 6). With increasing downslope distance from the dye application, the dye distribution in the topsoil successively decreased into narrow dye flowlines parallel to the slope (Fig. 6, Profile A3, A2 and A1). Interestingly, the dye pattern of the most downward lateral profile E (Figs. 3 and 6) was similar to the staining within or near to the dye application area (Fig. 7). In contrast, all frontal profiles further downslope (and outside) of the dye application area, namely A1, A2, B1, B2, C1, and C2 


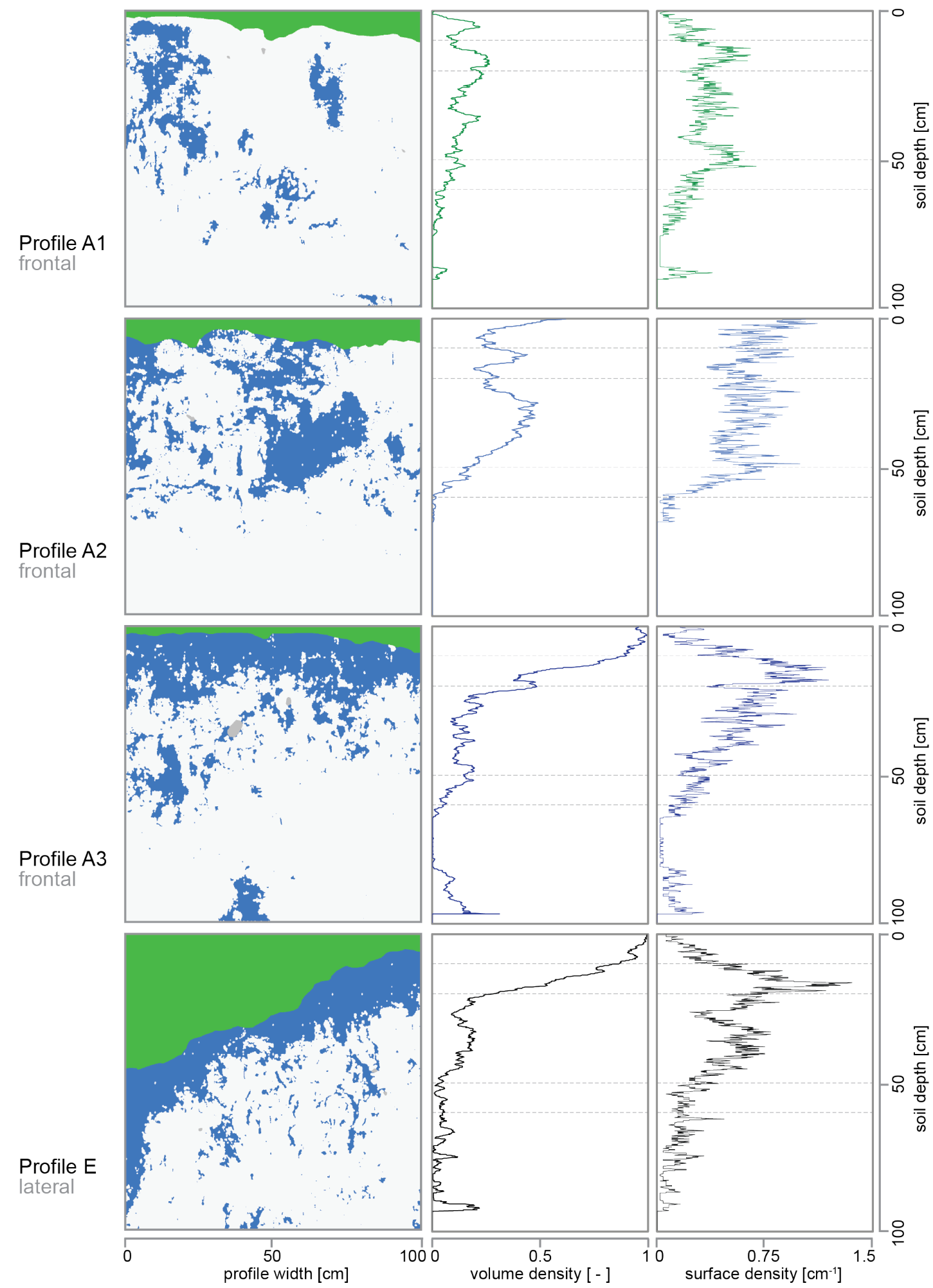

Fig. 6. Brilliant blue dye pattern (blue), surface topography/grass (green), and obstacles, e.g., stones (gray) together with its numerical representation in relation to the soil surface (interface green/blue) for selected profiles A1, A2, A3 and E. Volume density (VD) illustrates the dye coverage per soil depth. Low values of VD represent a low abundance of the dye (e.g., bypassing the soil matrix), whereas high values indicate a high abundance of the dye (e.g., complete matrix staining in the H horizon). Surface density (SD) illustrates the vertical distribution and dimension (size) of dye-stained structures in the soil profiles. The frontal profiles A1-A3 and the lateral profiles E are 2.0, 1.5, and $1.0 \mathrm{~m}$ downhill of the irrigation plot (see Fig. 2). Low values of SD represent few but, large structures (e.g., matrix flow in H horizon); high SD-values indicate many, but small dye-stained objects (e.g., macropores in Go horizon). 

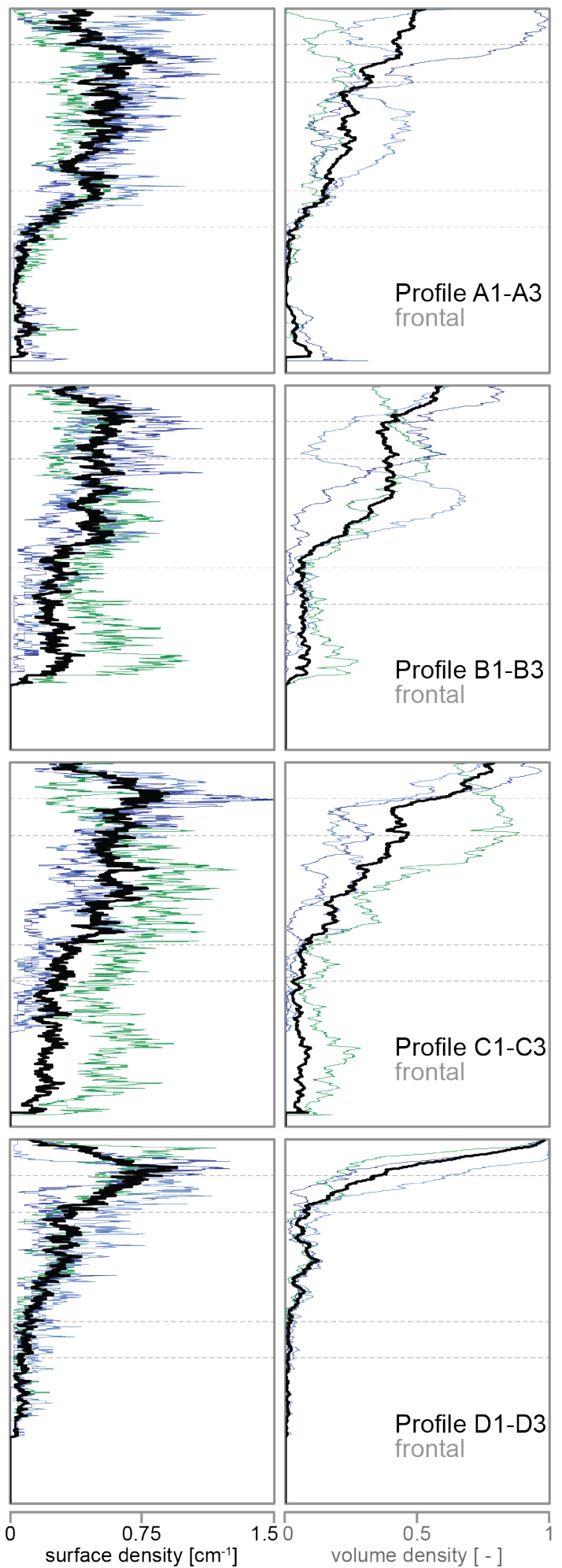
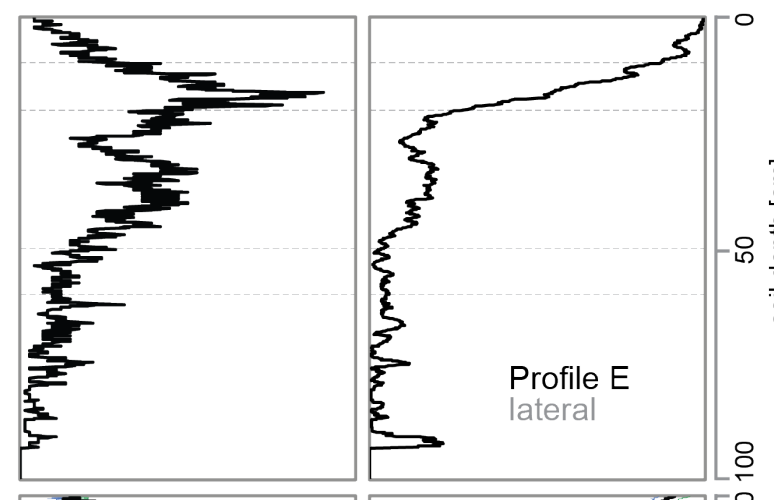

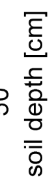

웅
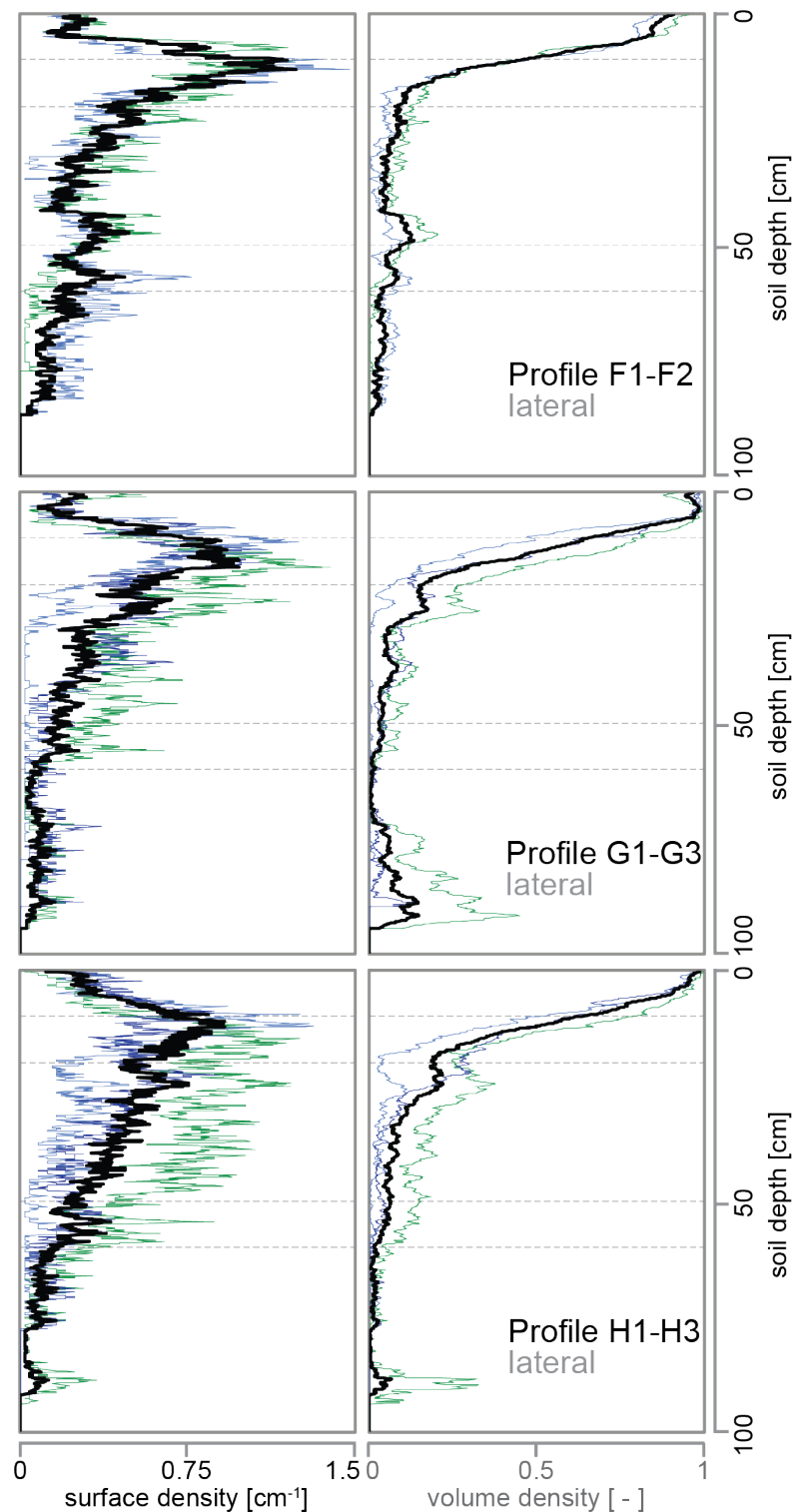

Fig. 7. Numerical representation of the dye-stained soil patterns of the $1 \mathrm{~m} \times 1 \mathrm{~m}$ soil profiles. The integrated frontal profiles A1-A3, B1-B3, C1-C3 are shown on the left, lateral profiles E, F1-F2, G1-G3 and H1-H3 are on the right. Surface density (SD) illustrates the vertical distribution and dimension (size) of dye-stained structures in the soil profiles. Volume density (VD) illustrates the dye coverage per soil depth. The black lines represent the SD or VD of the profile group (one value for A1, A2, A3). The colored lines illustrate the SD or VD of the individual profiles (green, bright blue, dark blue). The dashed gray lines represent the soil horizon boundaries of the gleysol in $0.1 / 0.2 \mathrm{~m}$ (H/Go horizon) and 0.5/0.6 m depths (Go/Gr horizon). 
(Fig. 2b) showed a high variability both in volume and surface density (Fig. 7).

\subsubsection{Lateral dye patterns}

Figures 3 and 6 show the observed stain structures of the lateral soil profile $\mathrm{E}$ (1.0 to $2.0 \mathrm{~m}$ downslope of the dye sprinkling area). In Fig. 3e box (a) marks the stained topsoil matrix (H horizon), box (b) illustrates the Go horizon with its staining of mainly worm burrows and box (c) slightly stained Gr horizon due to some dead tree roots. Box (d) shows a $0.5 \mathrm{~m}$ deep stained soil fracture in the Go horizon. The same soil fracture continued into the neighboring frontal profile $\mathrm{C} 1$ (not shown), where a large stained structure occurred in the Go horizon. Typically, macropores in the Go - mainly worm burrows - and the Gr horizons - mostly dead tree roots - did not show any interaction with the surrounding matrix. Larger stained soil structures, leading to higher surface density and a slightly increased volume density at depth of 0.25 to $0.5 \mathrm{~m}$, could be related to soil fractures in the Go horizon (Figs. 6 and 7, Profile E). Some of these fractures were still filled with liquid dye several days after the dye application and did not show any interaction with the soil matrix in the subsoil.

\subsubsection{Frontal dye patterns}

The frontal soil profiles A1-A3 (Fig. 6) showed that with increasing distance from the brilliant blue dye application field (Fig. 2) the dye staining of the $\mathrm{H}$ horizon - and thus the volume density (=dye coverage) at depths from 0 to $0.1 / 0.2 \mathrm{~m}$ - decreased from nearly 1 (A3) over 0.5 (A2) to less than 0.25 (A1). In profile A3 (1 m downslope of the brilliant blue application), the dye covered the entire $\mathrm{H}$ horizon (volume density $=1$ ), whereas the Go horizon was primarily stained due to worm burrows up to $0.6 \mathrm{~m}$ depth (low volume density, decreasing surface density from 0.2 to $0.6 \mathrm{~m}$ depth); staining below $0.9 \mathrm{~m}$ depth in the Gr horizon occurred due to some dead tree roots.

In profile A1 (2.0 m downslope/outside of dye application area), the $\mathrm{H}$ horizon was horizontally and vertically only partially stained. Our interpretation of this observation was that staining only occurs in shallow, saturated zones/channels in the $\mathrm{H}$ horizon on top of the percolation-inhibited Go horizon, resulting in sequentially stained structures in the underlying Go horizon due to a prominent soil fracture perpendicular to the slope (left side and center-right of profile A1). The limited staining in the Gr horizon of profile A1 can be explained by the few tree roots in the lower right corner of the profile and the closure of the soil fracture in the Gr horizon. The dye pattern in profile A2 (1.5 $\mathrm{m}$ downslope) differs from the A1 and A3 profiles (Fig. 6). Profile A2 shows strongly reduced staining in the $\mathrm{H}$ horizon (like A1), prominent staining of a soil fracture wall in the Go horizon (indicated by a rather constant surface density of 0.75 from 0.2 to $0.5 \mathrm{~m}$ depth combined with high volume density values), and no staining in the
Gr horizon due to the absence of deep tree roots and closure of the soil fracture in the Go horizon.

The profiles B1-B3 and C1-C3 (profile overlay in Fig. 7) show similar patterns of reduced topsoil staining with increasing distance from the dye application field, prominent Go horizon staining mainly due to soil fractures (indicated by volume densities in the range of 0.5 and surface densities between 0.5 and 0.75 ) and worm burrows (indicated by low volume densities and surface densities higher than 0.75$)$. In all soil profiles, the Gr horizon is only stained in the presence of dead tree roots. During the excavation, we observed soil fractures in two frontal profiles (A2 and C1) and one lateral profile (E, see Fig. 6) in the Go horizon, but none of these soil fractures reached to the bedrock. Soil fractures were mostly perpendicular to the slope's gradient and were more abundant at places (i) with changing inclination, mainly at steps or break-points, where the slope steepens, and are expected (ii) above bedrock outcrops at points with reduced soil depth.

\subsection{Runoff formation}

The long-term soil moisture data (Brönnimann et al., 2013) showed that the deeper soil layers were permanently saturated; yet they were not well drained and not able to substantially transfer water laterally due to their high clay content (Figs. 4 and 5). Illite and smectite, both typical clay minerals of molasse rocks, increased with depth from 25 weightpercent in the Go horizon to 35-40 weight-percent in the Gr horizon, resulting in low saturated hydraulic conductivities of $10^{-9}$ and $10^{-10} \mathrm{~m} \mathrm{~s}^{-1}$, respectively (Table 1, Brönnimann et al., 2013). Hence, the groundwater dynamics and discharge into the SSF drainage pipes in the deeper soil layer produced by natural rainfall events and the sprinkling experiments (Figs. 4 and 5) were not due to lateral preferential flow in the subsoil of the gleysol. Instead, groundwater and discharge dynamics were fed by artificial vertical short-cuts generated during the instrumentation of the test site. Specifically, the fully filtered wells and the preferential infiltration along the soil pit of the subsurface flow drainage pipes artificially connected the main lateral drainage in the topsoil - organic layer interflow - to our installations and instruments intended to monitor the dynamics of deeper soil layers (Figs. 4 and 5). This was clearly illustrated by the stained flowpaths of the brilliant blue experiment (Figs. 3, 6 and 7), which demonstrate the dominance of organic layer interflow in the $\mathrm{H}$ horizon as the primary runoff formation mechanism.

\section{Discussion}

Subsurface stormflow (SSF) is a prominent runoff-producing mechanism in most upland terrains. As SSF may enhance positive pore water pressures in steep terrain, SSF is a possible hydrological trigger of shallow landslides (Weiler et al., 2006). While some studies describe SSF as unsaturated flow 

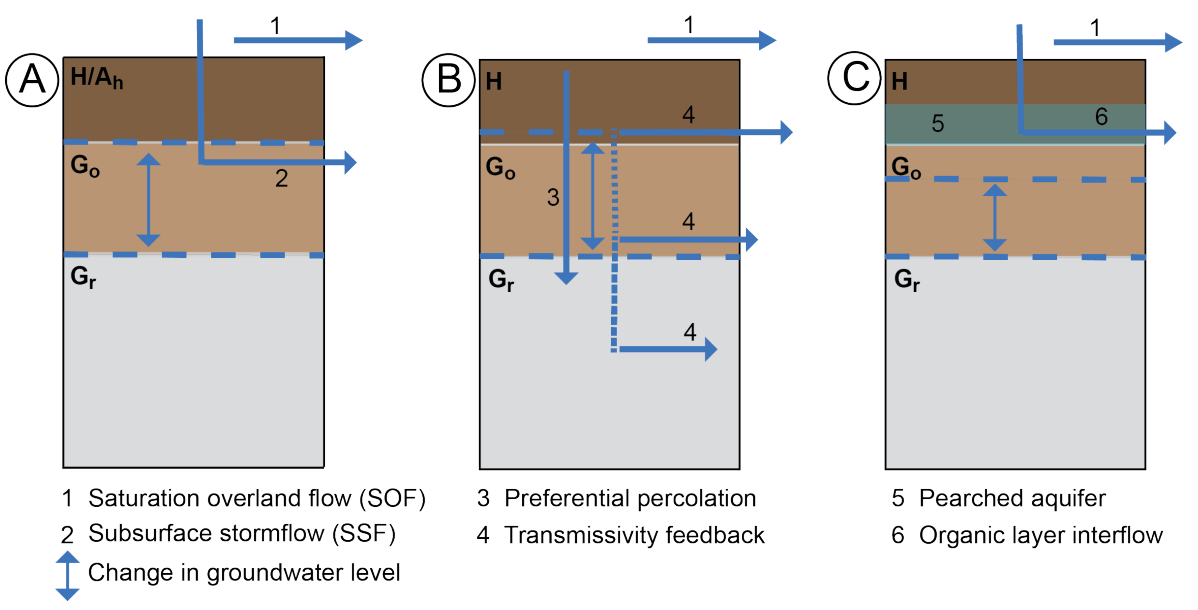

Fig. 8. Conceptual models for different types of subsurface stormflow (SSF) at the Rufiberg hillslope and the hydrology of soil types framework (HOST, after Boorman et al., 1995). SSF (2) is the dominant process, SOF (1) may occur at high precipitation rates. (A) HOST runoff response model F (gleysols): the groundwater level is rarely present in the Go horizon, thus SSF can occur in the Go horizon (e.g., soil pipes or soil matrix). (B) Conceptual model transmissivity feedback (4): preferential percolation (3) leads to a quick groundwater rise into more conductive soil layers. Depending on lateral permeability of the soil horizons, SSF evolves with the rising groundwater, generating runoff first in the Gr horizon, followed by Go and $\mathrm{H}$ horizons. (C) Conceptual model perched aquifer/organic layer interflow: rainfall quickly infiltrates, resulting in a perched aquifer (5) in the $\mathrm{H}$ horizon, which lateral discharges as saturated organic layer interflow (6). The Go/Gr horizons act as percolation barriers, which are not drained laterally.

in the unsaturated zone, the majority of studies have documented SSF in saturated or near-saturated soil layers, either due to (1) the rise of groundwater into more transmissive soil layers (Rohde, 1987), (2) lateral flow in a highly permeable soil layer with high infiltration capacity above a low permeable soil layer (Weiler et al., 2006), or as (3) lateral flow at the soil-bedrock interface (Tani, 1997; Tromp-van Meerveld and McDonnell, 2006).

\subsection{Sprinkling experiments}

For Switzerland, Scherrer and Naef (2003) developed a decision scheme to indicate the dominant hydrological flow processes for high-intensity rainfall events on temperate grassland hillslopes based on sprinkling experiments $\left(60 \mathrm{~m}^{2}\right.$ plots). This approach predicted saturation overland flow due to slowly saturating soils (SOF2) for the Rufiberg test site. The reason for the different results of Scherrer and Naef (2003) might originate from their focus on extreme hydrological events and experimental settings with irrigation rates of up to $100 \mathrm{~mm} \mathrm{~h}^{-1}$. However, such extreme rainfall intensities are far from the intensities measured during the August 2005 storm, which triggered shallow landslides at the Rufiberg. We conclude that rainfall intensities of $100 \mathrm{~mm} \mathrm{~h}^{-1}$ most probably would lead to significant SOF2 at the Rufiberg (Figs. 5 and 8), but this process is not likely to be responsible for triggering shallow landslides.

In the UK, Boorman et al. (1995) developed a method to predict the dominant runoff formation mechanisms based on soil information, called "hydrology of soil types" (HOST, Fig. 8). The dominant features of gleysols are prolonged saturation of the deeper soil layers ( $\mathrm{Gr}$ and Go horizon) with limited drainage associated with a lack of aeration, poor rooting conditions for plants, and poor bioturbation conditions for soil fauna (Gr horizon). Based on the two criteria (i) groundwater table in less than $2.0 \mathrm{~m}$ depth, and (ii) gleyed layer within $0.4 \mathrm{~m}$ of the soil surface, the HOST framework (Boorman et al., 1995) predicts a "runoff response model" - in the case of the Rufiberg's gleysol "HOST model F" with a dominance of "prolonged saturated subsoil flow" (= subsurface stormflow). HOST's prediction of "runoff response model F" matches the observed runoff formation process saturated subsurface stormflow surprisingly well (Fig. 8), although it was originally developed for a different environment and climate in the UK. HOST does not specify in which soil horizon this "prolonged saturated subsoil flow" occurs. However, HOST differentiates between "saturated soil flow" (e.g., HOST model G) and "saturated subsoil flow" (HOST model F). Thus the HOST model F's saturated subsoil flow most likely does not correspond exactly to shallow subsurface stormflow or organic layer interflow (Fig. 8).

\subsubsection{Soil moisture response}

Thickness and drainable porosity of hillslope soils - the pore volume between field capacity and saturation - are thought to represent first-order controls on subsurface stormflow (Hopp and McDonnell, 2009; Uchida et al., 2006; Weiler and McDonnell, 2004). However, a rather thin shallow organic topsoil of $0.1-0.2 \mathrm{~m}$ clearly dominated the discharge response of the gleysol hillslope with its high lateral 
permeability at (near)-saturated conditions. Our soil moisture measurements at four depths $(0.25,0.7,1.1$, and $1.5 \mathrm{~m}$ depth $)$ in four soil pits (Fig. 1) at the Rufiberg test site together with a soil sample analysis in the lab (Table 1; Maries, 2011) indicate a low permeability of the subsoil horizons (Go and Gr horizon). They exhibited persistently high soil moisture values, both for the experiments (Figs. 4 and 5) and for the continuous monitoring (Brönnimann et al., 2013).

At slopes with a laterally high-permeable topsoil layer typically paralleled with a high infiltration capacity - above a low-permeable soil layer (Fig. 8), lateral matrix flow can be a prominent subsurface flow process (Weiler et al., 2006). However, our soil moisture measurements at $0.25 \mathrm{~m}$ depth (Figs. 4 and 5) were not able to identify the perched aquifer of the "organic layer interflow" (Fig. 8), which laterally drained the organic topsoil (H horizon), as (i) volumetric water content (VWC) maxima at $0.25 \mathrm{~m}$ depth were lower than VWC values at 1.1 and $1.5 \mathrm{~m}$ depth, and (ii) none of the TDRs were installed directly in the $\mathrm{H}$ horizon. Hence, soil moisture observations provide optimal information in soil layers with high drainable porosity, e.g., (near) saturation during storm events but mostly near field capacity when they are well drained. Consequently, test site instrumentation and continuous monitoring of soil moisture should focus on soil layers with high moisture variability and high drainable porosity - even if they are rather thin $(<0.2 \mathrm{~m})$.

\subsubsection{Groundwater response}

Our instrumentation with fully filtered monitoring wells, which is widespread in many research catchments e.g., Maimai in New Zealand (Brammer and McDonnell, 1996; McGlynn et al., 2002), Tanakami Mountain Hillslope in Japan (Asano et al., 2002), Panola Mountain Research Catchment in the USA (Tromp-van Meerveld and McDonnell, 2006), Black Forest Foothill Research Hillslope, Germany (Bachmair and Weiler, 2012) - was not able to attribute groundwater dynamics to the runoff formation processes of individual soil layers (Figs. 4, 5, and 8). Although we observed significant groundwater rises during the sprinkling experiments (Figs. 4 and 5), these groundwater data were misleading, supporting the runoff formation process transmissivity feedback (Fig. 8b). This interpretation was rejected based on the results of the dye tracer experiment (Figs. 6 and 7), which was clearly consistent with organic layer interflow along a perched aquifer (Fig. 8c). Our groundwater instrumentation with fully filtered monitoring wells mostly failed to identify the dominant runoff formation processes or to test our hypotheses related to hydrological triggers of shallow landslides.

\subsubsection{Discharge response}

When interpreting our discharge response data without the dye experiment, the sprinkling experiments suggested the following interpretation:

1. Up to rainfall intensities of $20 \mathrm{~mm} \mathrm{~h}^{-1}$, subsurface stormflow (SSF) was the dominant runoff mechanism. Significant contributions of SOF to runoff occurred when rainfall intensities continuously exceeded a threshold of $20 \mathrm{~mm} \mathrm{~h}^{-1}$ for longer periods (Figs. 4 and 5). The precipitation probably exceeded the lateral drainage capacity of the $\mathrm{H}$ horizon (organic layer interflow) resulting in return flow. In the second experiment, SOF dominated the runoff response quickly after the onset of SOF (after approx. 50 min sprinkling with an intensity of $25 \mathrm{~mm} \mathrm{~h}^{-1}$ ), as long as rainfall intensities remained high (Fig. 5). However, SOF was sensitive to short interruptions $(5 \mathrm{~min}$ ) of the sprinkling, e.g., at times when the filters of the sprinkling system were cleaned (Fig. 5, black triangles).

2. Runoff occurred first in the $1 \mathrm{~m} \mathrm{SSF}$ drainage, shortly followed by the shallow $0.25 \mathrm{~m} \mathrm{SSF}$ drainage (Fig. 4). The maximum lateral drainage capacity was higher at $0.25 \mathrm{~m}$ depth than at $1.0 \mathrm{~m}$ depth (Figs. 4 and 5). Together this could be interpreted as transmissivity feedback: first water infiltrated and percolated to the deep soil horizon. With time, groundwater rose (Figs. 4 and 5) and the shallower soil layers with a higher lateral permeability began to drain the soil profile (Fig. 8b).

\subsubsection{Tracer response}

When interpreting our tracer data without the dye experiment, the sprinkling experiments suggested the following interpretation:

1. The tracer fluorescein (Table 2) - applied as line injection at the $\mathrm{H}$ horizon $0.05 \mathrm{~m}$ below the soil surface before the onset of the sprinkling in the upper part of the sprinkling area (Fig. 1b) - moved quickly through the soil and showed a first tracer breakthrough in the $0.25 \mathrm{~m} \mathrm{SSF}$ drainage, followed by a delayed and dampened tracer breakthrough in the $1.0 \mathrm{~m} \mathrm{SSF}$ drainage (Fig. 4). Shortly after the onset of SOF, SOF dominated the fluorescein response (Figs. 4 and 5).

2. The tracer $\mathrm{NaCl}$ (Table 2) was applied to an additional $100 \mathrm{~L}$ sprinkling water tank during the change of the irrigation rate. For both sprinkling experiments the tracer breakthrough occurred with a short delay in all three discharge levels, at depths of 1.0 and $0.25 \mathrm{~m}$ SSF drainage, as well as at $0.05 \mathrm{~m}$ depth in the surface flow collector, respectively (Figs. 4 and 5). In both experiments the $\mathrm{NaCl}$ concentration reached its 
highest values in the surface flow collector, followed by the $0.25 \mathrm{~m}$ SSF drainage with a much lower peak, and finally the lowest peak occurred in the $1.0 \mathrm{~m} \mathrm{SSF}$ drainage (Figs. 4 and 5). The different settings of the two sprinkling experiments had little impact on the $\mathrm{NaCl}$ breakthrough curve. The main differences were (1) the absolute $\mathrm{NaCl}$ concentration - which can be seen as different event and pre-event water mixing ratios - and (2) the quicker tracer recession of the $0.25 \mathrm{~m}$ SSF drainage compared to $1.0 \mathrm{~m} \mathrm{SSF}$ drainage in the second experiment (Fig. 5). This last finding can be explained by dilution due to different runoff volumes at the different soil levels with increased runoff at $0.25 \mathrm{~m}$ SSF drainage compared to $1.0 \mathrm{~m}$ depth till the end of the sprinkling (Fig. 5).

3. Together, the data from both tracers suggested that the higher soil layers have a higher lateral permeability, but the lower layers are activated first. The "higher" soil layers generate more runoff after the groundwater rises (Figs. 4, 5 and 8b), which would be consistent with the runoff mechanism transmissivity feedback (Rohde, 1987).

The subsurface flow velocities derived by fluorescein application at the Rufiberg were consistent with hillslope studies with comparable soil properties and similar climate conditions (e.g., Weiler et al., 1998; Wienhöfer et al., 2009, Table 4). Graham et al. (2010) conducted hillslope scale irrigation and line tracer experiments with bromide, together with a brilliant blue dye tracer and excavation experiment at the well-studied Maimai catchment in New Zealand to identify dominant flowpaths and to characterize the role of bedrock topography and permeability at the hillslope scale. Their findings suggested "that major controls of subsurface flow were the microscale bedrock topography, bedrock permeability and lateral subsurface velocities" (Graham et al., 2010). In spite of the similarities between Maimai and $\mathrm{Ru}-$ fiberg (slope's gradient $\sim 30^{\circ}$, humid climate, relatively wet soils with a high infiltration capacity, prominent organic topsoil, conglomerate bedrock, similar precipitation threshold (Table 3), and comparable lateral subsurface flow velocities (Table 4)), the findings at Rufiberg were quite different than those at Maimai by Graham et al. (2010).

\subsection{Dye tracer experiment}

Dye tracer studies are carried out to (i) qualitatively visualize flowpaths in soils (Flury et al., 1994), and (ii) to quantitatively identify flow types in macroporous soils (Bogner et al., 2008, 2013; Weiler and Flühler, 2004). The brilliant blue experiment clearly identified the hydrological active soil horizons - in the case of the Rufiberg gleysol, the mixed organic and muck $H$ horizon - and thus changed our perception of the hydrological processes based on soil moisture, groundwater, surface and subsurface discharge data of two sprinkling experiments and year-long natural-rainfall observation. Organic layer interflow (Weiler and McDonnell, 2004) - also called biomate flow (Sidle et al., 2007) - could be identified as the primary runoff formation process at the Rufiberg pasture hillslope.

Interestingly, organic layer interflow is commonly attributed to forested hillslopes (Buttle and Turcotte, 1999; Sidle et al., 2007; Ward and Robinson, 1990; Weiler and McDonnell, 2004), but rarely to pasture or grassland hillslopes. This may be partly due to the focus on forested slopes in hillslope hydrology research and partly due to instrumental limitations, as this shallow subsurface flow is difficult to distinguish from saturation overland flow - which is expressed in the term pseudo-overland flow (McDonnell et al., 1991). Hence, it is important to differentiate between saturation overland flow (SOF) and organic layer interflow as this has major consequences for (i) fluxes of solutes - e.g., nutrients or agro-chemicals - from land to water and (ii) the hydrochemical fingerprint of streams, which are partly formed by the flowpath(s) linking soil- and stream-water chemistry (Seibert et al., 2009).

The brilliant blue dye staining data (Figs. 6 and 7) are consistent with the theoretical assumption that the distribution of lateral flow of water across the vertical soil profile strongly decreases with depth, reflecting the hydrologic properties of the soil layers and contrasting the antecedent soil moisture distribution of the gleysol (Figs. 4 and 5). The dye-stained profiles indicate that the difference between the initial soil moisture content and saturated conditions in the Go and $\mathrm{Gr}$ horizons is small (small drainable porosity). As the subsoil matrix is permanently (Gr) or almost (Go) saturated, percolating precipitation has mostly to fill the vertical macropores to saturate the subsoil horizons.

In contrast to the $\mathrm{H}$ horizon, the deeper Go and Gr horizons did not contribute to lateral drainage of the hillslope (Figs. 6 , 7 and 8c). However, soil fractures and dead tree roots potentially bypass the deeper soil layers and thus may recharge the bedrock aquifers. Our $5 \mathrm{~m} \times 5 \mathrm{~m}$ excavation of the brilliant blue dye did not detect dye-stained features connecting to the bedrock, but during the two sprinkling experiments at the $10 \mathrm{~m} \times 10 \mathrm{~m}$ irrigation plot, groundwater in the underlying bedrock (borehole nests B1 and B2, Fig. 1) responded quickly to the irrigation (Brönnimann et al., 2013).

We did not find any evidence of lateral flow in the Go and Gr horizon, although we were looking for such deeper lateral flowpaths, especially in the vicinity of the drainage pipes. Instead, the dominant flowpaths towards the pipes were clearly labeled by brilliant blue in the organic layer, which then vertically percolated towards the drainages along the refilled trench-walls (= preferential vertical flowpaths, which were created during the installation of the drainage pipes). Thus, brilliant blue stained lateral preferential flowpaths in the H horizon more than $3 \mathrm{~m}$ downslope outside of the dye application area. Furthermore, the Gr horizon would quickly lose its grayish color in case of frequent drainage due to oxidation 
of $\mathrm{Fe}^{2+}$ to $\mathrm{Fe}^{3+}$ (frequent drainage temporarily aerates the macropores). The oxidation of $\mathrm{Fe}^{2+}$ to $\mathrm{Fe}^{3+}$ is relatively fast, but the reverse reaction is slow. Therefore, the gray color is an indication of persistent saturation.

\subsection{Runoff formation and shallow landslides}

Quick infiltration and efficient lateral drainage - caused by a runoff formation process called organic layer interflow (Weiler and McDonnell, 2004) - prevails in the topsoil's $\mathrm{H}$ horizon at the unchannelized, zero-order Rufiberg basin (Fig. 8c). An experimental runoff formation study at Swiss grassland gleysol hillslopes identified infiltration and lateral subsurface flow in the A-horizon as dominant runoff formation mechanism (70\% of total runoff, Weiler et al., 1998). In contrast, the (nearly) saturated deeper soil horizons of the Rufiberg gleysol (H-Go-Gr) - the Go and especially the $\mathrm{Gr}$ horizon - are percolation barriers and show no evidence of lateral drainage. The deeper gley horizons act rather as a "dead end" of water flow with storage in vertical macropores and insignificant matrix interaction. The poor drainage properties of gleysols may explain the absence of persistent springs or streams at the Rufiberg in spite of humid climate conditions.

A few infiltration hot spots created by soil fractures perpendicular to the slope effectively transferred dye-label water into deeper gley layers (Fig. 3e) - mostly into the Go, rarely into the Gr horizon. Worm burrows are a prominent staining feature partially penetrating the periodically aerated Go horizon, mostly in the vertical direction, forming dyestained "dead ends" (Fig. 3e). Dead tree roots penetrated the Gr horizon and thus vertically distribute the brilliant blue dye (Fig. 3e). We could not identify any dye-stained fractures connecting to the soil-bedrock interface. However, neither soil pipes - e.g., by worm burrows, bioturbation by other organisms, or tree roots - nor soil fractures drained the deeper soil layers laterally. This is consistent with the hydrological characteristics of gleysols (Fig. 8a), e.g., described in the Hydrology of Soil Types (HOST) framework by Boorman et al. (1995). The dominant features of gleysols are (i) prolonged saturation of the deeper soil layers (Gr and Go horizon) and (ii) limited drainage associated with a lack of aeration, poor rooting conditions for plants and poor bioturbation conditions for soil fauna (Gr horizon). Finally, we could not detect any dye staining at the soil-bedrock interface during our experiments. These findings are in contrast to many hillslope hydrology studies, where the soil-bedrock interface is described as a prominent lateral drainage feature (Onda et al., 2001; Tani, 1997; Tromp-van Meerveld and McDonnell, 2006; Uchida et al., 2002, 2005).

In the context of shallow landslides, the hydrologic properties of the $\mathrm{Gr}$ horizon form at least locally an aquiclude/aquitard potentially leading to a confined bedrock aquifer. The hydraulic conductivities of the soil matrix of the subsoil's Go and Gr horizons (Brönnimann et al.,
2013) are too low to build up dynamic water tables in the bedrock without preferential flowpaths. However, we could not identify preferential flow structures recharging the bedrock aquifer with the small-scale dye experiment. On a larger scale however, recharge structures like deep soil fractures, dead tree roots or bedrock outcrops may bypass the subsoil matrix and funnel shallow subsurface stormflow from the $\mathrm{H}$ horizon directly into the bedrock aquifer. Such quick recharge could explain local pore water pressure peaks in the confined bedrock aquifer - which were observed at the Rufiberg test site during the sprinkling experiments and under natural rainfall conditions by Brönnimann et al. (2013) - and thus may trigger shallow landslides.

\section{Conclusions}

In this work we studied the dominant runoff formation processes on a $30^{\circ}$-steep pasture hillslope. Although the two sprinkling experiments could have been interpreted as having subsurface stormflow generated by groundwater rising into higher conductive soil layers (transmissivity feedback), we rejected this interpretation based on our results from the brilliant blue experiment, changing our perception of the hydrological processes at this hillslope. The dye tracer experiment clearly showed quick infiltration and efficient lateral drainage by shallow subsurface stormflow in the topsoil's organic $\mathrm{H}$ horizon (saturated organic layer interflow), whereas the subsoil horizons of the gleysol (H-Go-Gr) were percolation barriers and showed no evidence of lateral drainage. Based on all available information, organic layer interflow was identified as the primary runoff formation process at the Rufiberg test site that generated discharge when total rainfall exceeded a threshold of 9 to $21 \mathrm{~mm}$.

A second question in this study was how rainfall intensities impact runoff formation. Based on the sprinkling experiments with different intensities, we concluded that the shallow organic topsoil (a 0.1 to $0.2 \mathrm{~m}$-thick $\mathrm{H}$ horizon) could drain water flows laterally that correspond to up to $20 \mathrm{~mm} \mathrm{~h}^{-1}$ rainfall. Lateral preferential flow structures in the deeper soil horizons or at the soil-bedrock interface could not be identified. Accordingly, the subsoil of the Rufiberg hillslope seemed to be not significantly drained; instead vertical macropores were found to be dead-end storage space with minimal exchange with the soil matrix. Rainfall intensities continuously above $20 \mathrm{~mm} \mathrm{~h}^{-1}$ for longer periods (> $20 \mathrm{~min}$ ) produced significant saturation overland flow. This secondary runoff formation process dominated the discharge response when initial rainfall intensities were above this threshold.

Finally, in the context of shallow landslides the hydrologic soil properties of the Go and Gr horizons of the gleysol acted as an infiltration and exfiltration barrier, thus producing significant lateral saturated drainage in the topsoil and possibly a confined aquifer in the bedrock. Soil fractures, dead 
tree roots, and bedrock outcrops may efficiently recharge the bedrock aquifer, which could explain quick rises in positive pore water pressures and thus potentially trigger landslides. Soil fractures were mostly perpendicular to the slope's gradient and are expected to be more abundant at places (i) with changing inclination, mainly at steps or break-points were the slope steepens, and (ii) above bedrock outcrops, mostly at points with reduced soil depth. Future hillslope hydrology research should first distinguish accurately between saturation overland flow and shallow subsurface flow, and second adapt its instrumentation accordingly, as organic layer interflow might be a prominent runoff formation process not only in forested catchments, but also at grassland or pasture hillslopes.

Acknowledgements. The authors would like to thank the Unterallmend-Korporation Arth for the authorization to carry out experiments on their ground and Markus Weiler (University of Freiburg) for providing IDL code for the brilliant blue image analysis. We also thank the TRAMM (Triggering of Rapid Mass Movements in steep terrain) project team for the technical and logistical support with the instrumentation, maintenance, and fieldwork.

Edited by: T. Bogaard

\section{References}

Anderson, A. E., Weiler, M., Alila, Y., and Hudson, R. O.: Dye staining and excavation of a lateral preferential flow network, Hydrol. Earth Syst. Sci., 13, 935-944, doi:10.5194/hess-13-9352009, 2009.

Anderson, S. P., Dietrich, W. E., Montgomery, D. R., Torres, R., Conrad, M. E., and Loague, K.: Subsurface flow paths in a steep, unchanneled catchment, Water Resour. Res., 33, 26372653, doi:10.1029/97WR02595, 1997.

Asano, Y., Uchida, T., and Ohte, N.: Residence times and flow paths of water in steep unchannelled catchments, Tanakami, Japan, J. Hydrol., 261, 173-192, 2002.

Bachmair, S. and Weiler, M.: Hillslope characteristics as controls of subsurface flow variability, Hydrol. Earth Syst. Sci., 16, 36993715, doi:10.5194/hess-16-3699-2012, 2012.

Bachmair, S., Weiler, M., and Nützmann, G.: Controls of land use and soil structure on water movement: Lessons for pollutant transfer through the unsaturated zone, J. Hydrol., 369, 241-252, doi:10.1016/j.jhydrol.2009.02.031, 2009.

Bezzola, G. R. and Hegg, C.: Bericht über die Hochwasserereignisse 2005, available from: http://www.news.admin.ch/ NSBSubscriber/message/attachments/1123.pdf, last access: 20 June 2013, Bundesamt für Umwelt (BAFU), Bern, 25 pp., 2005

Bezzola, G. R. and Hegg, C.: Ereignisanalyse Hochwasser 2005, Teil 1 - Prozessse, Schäden und erste Einordnung, available from: http://www.bafu.admin.ch/publikationen/publikation/ 00044/index.html?lang=de, last access: 20 June 2013, Bundesamt für Umwelt (BAFU), Bern, 215 pp., 2007.
Bezzola, G. R. and Hegg, C.: Ereignisanalyse Hochwasser 2005 , Teil 2 - Analyse von Prozessen, Massnahmen und Gefahrengrundlagen, available from: http://www.bafu.admin.ch/ publikationen/publikation/00100/index.html?lang=de, last access: 20 June 2013, Bundesamt für Umwelt (BAFU), Bern, 426 pp., 2008.

Bogner, C., Wolf, B., Schlather, M., and Huwe, B.: Analysing flow patterns from dye tracer experiments in a forest soil using extreme value statistics, Eur. J. Soil Sci., 59, 103-113, doi:10.1111/j.1365-2389.2007.00974.x, 2008.

Bogner, C., Trancón y Widemann, B., and Lange, H.: Characterising flow patterns in soils by feature extraction and multiple consensus clustering, Ecol. Inform., 15, 44-52, doi:10.1016/j.ecoinf.2013.03.001, 2013.

Boorman, D. B., Hollist, J. M., and Lilly, A.: Hydrology of soil types: a hydrologically based classification of the soils of the United Kingdom, IH Report No. 126, Institute of Hydrology (IH), Wallingford, 1995.

Brammer, D. D. and McDonnell, J. J.: An evolving perceptual model of hillslope flow at the Maimai catchment, in: Advances in hillslope processes, vol. 1, edited by: Anderson, M. G. and Brooks, S. M., John Wiley \& Sons Ltd., New York, 35-60, 1996.

Brönnimann, C., Stähli, M., Schneider, P., Seward, L., and Springman, S. M.: Bedrock exfiltration as a triggering mechanism for shallow landslides, Water Resour. Res., 49, 5155-5167, doi:10.1002/wrcr.20386, 2013.

Buttle, J. M. and Turcotte, D. S.: Runoff processes on a forested slope on the Canadian shield, Nord. Hydrol., 30, 1-20, 1999.

Flury, M., Flühler, H., Jury, W. A., and Leuenberger, J.: Susceptibility of soils to preferential flow of water?: A field study, Water Resour. Res., 30, 1945-1954, 1994.

Forrer, I., Papritz, A., Kasteel, R., Flühler, H., and Luca, D.: Quantifying dye tracers in soil profiles by image processing, Eur. J. Soil Sci., 51, 313-322, 2000.

Geiger, H., Röthlisberger, G., Stehli, A., and Zeller, J.: Extreme Punktregen unterschiedlicher Dauer und Wiederkehrperioden 1901-1970, available from: http://www.hydrologie.unibe. ch/hades/hades/tafel24.html, Bundesamt für Umwelt (BAFU), Bern, Switzerland, 1992.

Graham, C. B., Woods, R. A., and McDonnell, J. J.: Hillslope threshold response to rainfall: (1) A field based forensic approach, J. Hydrol., 393, 65-76, doi:10.1016/j.jhydrol.2009.12.015, 2010.

Haught, D. R. W. and Tromp-van Meerveld, I.: Spatial variation in transient water table responses: differences between an upper and lower hillslope zone, Hydrol. Process., 25, 3866-3877, 2011.

Hopp, L. and McDonnell, J. J.: Connectivity at the hillslope scale: identifying interactions between storm size, bedrock permeability, slope angle and soil depth, J. Hydrol., 376, 378-391, 2009.

Hopp, L., McDonnell, J. J., and Condon, P.: Lateral subsurface flow in a soil cover over waste Rock in a humid temperate environment, Vadose Zone J., 10, 332-344, 2011.

Iverson, R. M.: Landslide triggering by rain infiltration, Water Resour. Res., 36, 1897-1910, 2000.

Jensen, H., Lang, H. and Rinderknecht, J.: Extreme Punktregen unterschiedlicher Dauer und Wiederkehrperioden 19011970, available from: http://www.hydrologie.unibe.ch/hades/ hades/tafel_242.html, Bundesamt für Umwelt (BAFU), Bern, Switzerland, 1997. 
Lambe, W. T. and Whitman, R. V.: Soil Mechanics, SI version, J. Wiley and Sons, New York, 1979.

Maries, G.: ETH Z.: Strength and geophysical profiling of a study site at Rufiberg, Canton Schwyz, CH, ETHZ, Zürich, Switzerland, 98 pp., 2011.

McDonnell, J. J., Owens, I. F., and Stewart, M.: A case study of shallow flow path in a steep zero-order basin, Water Resour. Bull., 27, 679-685, 1991.

McGlynn, B. L., McDonnell, J. J., and Brammer, D. D.: A review of the evolving perceptual model of hillslope flowpaths at the Maimai catchments, New Zealand, J. Hydrol., 257, 1-26, 2002.

Mosley, M. P.: Streamflow generation in a forested watershed, New Zealand, Water Resour. Res., 15, 795-806, 1979.

Onda, Y., Komatsu, Y., Tsujimura, M., and Fujihara, J.: The role of subsurface runoff through bedrock on storm flow generation, Hydrol. Process., 15, 1693-1706, doi:10.1002/hyp.234, 2001.

Rohde, A.: The origin of streamwater traced by Oxygen-18, Uppsala University, Uppsala, 260 pp., 1987.

Scherrer, S. and Naef, F.: A decision scheme to indicate dominant hydrological flow processes on temperate grassland, Hydrol. Process., 17, 391-401, 2003.

Schmid, F., Fraefel, M., and Hegg, C.: Unwetterschäden in der Schweiz 1972-2002: Verteilung, Ursachen, Entwicklung, Wasser Energ. Luft, 96, 21-28, 2004.

Seibert, J., Grabs, T., Köhler, S., Laudon, H., Winterdahl, M., and Bishop, K.: Linking soil- and stream-water chemistry based on a Riparian Flow-Concentration Integration Model, Hydrol. Earth Syst. Sci., 13, 2287-2297, doi:10.5194/hess-13-22872009, 2009.

Serra, J.: Image analysis and mathematical morphology, vol. 1, Academic Press, San Diego, 1988.

Sidle, R. C., Hirano, T., Gomi, T., and Terajima, T.: Hortonian overland flow from Japanese forest plantations - an aberration, the real thing, or something in between?, 21, 3237-3247, doi:10.1002/hyp.6876, 2007.

Sklash, M. G., Stewart, M. K., and Pearce, A. J.: Storm runoff generation in humid water catchments: 2 . A case study for hillslope and low-order stream response, Water Resour. Res., 22, 12731282, 1986.

Springman, S. M., Askarinejad, A., Casini, F., Friedel, S., Kienzler, P., Teysseire, P., and Thielen, A.: Lessons learnt from field tests in some potentially unstable slopes in Switzerland, Acta Slov. Geotech., 1, 5-29, 2012.

Tani, M.: Runoff generation processes estimated from hydrological observations on a steep forested hillslope with a thin soil layer, J. Hydrol., 200, 84-109, doi:10.1016/S0022-1694(97)00018-8, 1997.

Topp, G. C., Davis, J. L., and Annan, A. P.: Electromagnetic Determination of Soil Water Content: Measurements in Coaxial Transmission Lines, Water Resour. Res., 16, 574-582, 1980.

Tromp-van Meerveld, I. and McDonnell, J. J.: Threshold relations in subsurface stormflow: 2. The fill and spill hypothesis, Water Resour. Res., 42, W02411, doi:10.1029/2004WR003800, 2006.
Tromp-van Meerveld, I. and Weiler, M.: Hillslope dynamics modeled with increasing complexity, J. Hydrol., 361, 24-40, doi:10.1016/j.jhydrol.2008.07.019, 2008.

Uchida, T., Kosugi, K., and Mizuyama, T.: Effects of pipe flow and bedrock groundwater on runoff generation in a steep headwater catchment in Ashiu, central Japan, Water Resour. Res., 38, 715724, 2002.

Uchida, T., Tromp- van Meerveld, I., and McDonnell, J. J.: The role of lateral pipe flow in hillslope runoff response: an intercomparison of non-linear hillslope response, J. Hydrol., 311, 117-133, 2005.

Uchida, T., McDonnell, J. J., and Asano, Y.: Functional intercomparison of hillslopes and small catchments by examining water source, flowpath and mean residence time, J. Hydrol., 327, 627642, doi:10.1016/j.jhydrol.2006.02.037, 2006.

Van Asch, T. W. J., Buma, J., and Van Beek, L. P. H.: A view on some hydrological triggering systems in landslides, Geomorphology, 30, 25-32, 1999.

Ward, R. C. and Robinson, M.: Principles of hydrology, McGrawHill, New York, 1990.

Weibel, E. R.: Stereological methods, in: Practical methods for biological morphometry, vol. 1, Academic Press, London, 1979.

Weiler, M.: Mechanisms controlling macropore flow during infiltration Dye tracer experiments and simulations, ETH Zürich, 150 pp., 2001.

Weiler, M. and Flühler, H.: Inferring flow types from dye patterns in macroporous soils, Geoderma, 120, 137-153, doi:10.1016/j.geoderma.2003.08.014, 2004.

Weiler, M. and McDonnell, J. J.: Virtual experiments: a new approach for improving process conceptualization in hillslope hydrology, J. Hydrol., 285, 3-18, doi:10.1016/s00221694(03)00271-3, 2004.

Weiler, M., Naef, F., and Leibundgut, C.: Study of runoff generation on hillslopes using tracer experiments and a physically-based numerical hillslope model, in: Hydrology, Water Resources and Ecology in Headwaters, IAHS Publ. no. 248, Proceedings of the HeadWater'98 Conference, Meran, Italien, 353-360, 1998.

Weiler, M., McDonnell, J. J., Tromp-van Meerveld, I., and Uchida, T.: 112: Subsurface Stormflow, in: Encyclopedia of Hydrological Sciences, edited by: Anderson, M. G. and McDonnell, J. J., John Wiley \& Sons, New York, 1719-1732, 2006.

Wienhöfer, J., Germer, K., Lindenmaier, F., Färber, A., and Zehe, E.: Applied tracers for the observation of subsurface stormflow at the hillslope scale, Hydrol. Earth Syst. Sci., 13, 1145-1161, doi:10.5194/hess-13-1145-2009, 2009.

Zuidema, P. K.: Die Hydraulik der Abflussbildung bei Starkniederschlägen - Eine Untersuchung mit Hilfe numerischer Modelle unter Verwendung plausibler Bodenkennwerte, ETH Zürich., 162 pp., 1985. 